\title{
Circulating adiponectin levels in various malignancies: an updated meta-analysis of 107 studies
}

\author{
Tai Wei ${ }^{1, *}$, Peng Ye ${ }^{1, *}$, Xin Peng ${ }^{1}$, Li-Ling Wu $\mathbf{u}^{2}$ and Guang-Yan $\mathbf{Y u}^{1}$ \\ ${ }^{1}$ Department of Oral and Maxillofacial Surgery, Peking University School and Hospital of Stomatology, Beijing, China \\ 2 Department of Physiology and Pathophysiology, Peking University Health Science Center, Key Laboratory of Molecular \\ Cardiovascular Sciences, Ministry of Education, and Beijing Key Laboratory of Cardiovascular Receptors Research, Beijing, \\ China \\ * These authors have contributed equally to this work \\ Correspondence to: Li-Ling Wu, email: pathophy@bjmu.edu.cn \\ Guang-Yan Yu, email: gyyu@263.net \\ Keywords: adiponectin, malignancy, biomarker, diagnosis, meta-analysis \\ Received: December 15, 2015 Accepted: April 16, $2016 \quad$ Published: April 22, 2016
}

\section{ABSTRACT}

Early detection of cancers is challenging for lack of specific biomarkers. Adiponectin is an adipokine predominantly derived from adipocytes and hypoadiponectinemia has been reported to associate with risk of many types of cancers. However, available evidence is controversial. Some studies show that increased adiponectin levels correlate with cancer risk. Therefore, we performed a meta-analysis of the association between circulating adiponectin levels and cancer development. A systematic search of PubMed, EMBASE, Wiley Online Library and Cochrane Library was conducted for eligible studies involving circulating adiponectin and malignancies from inception to August 8, 2015. Standard mean differences (SMDs) with $95 \%$ confidence intervals ( $95 \%$ CIs) were calculated by use of a random-effect model. Funnel plot and Egger's linear regression test were conducted to examine the risk of publication bias. 107 studies were included with 19,319 cases and 25,675 controls. The pooled analysis indicated that circulating adiponectin levels were lower in patients with various cancers than in controls, with a pooled SMD of -0.334 $\mu \mathrm{g} / \mathrm{ml}(95 \% \mathrm{CI},-0.465$ to $-0.203, P=0.000)$. No evidence of publication bias was observed. Circulating high molecular weight adiponectin levels were also lower in cancer patients than in controls, with a pooled SMD of $-0.502 \mu \mathrm{g} / \mathrm{ml}(95 \% \mathrm{CI},-0.957$ to $-0.047, P=0.000$ ). This meta-analysis provides further evidence that decreased adiponectin levels is associated with risk of various cancers. Hypoadiponectinemia may represent a useful biomarker for early detection of cancers.

\section{INTRODUCTION}

Cancer, a major cause of human mortality, has been a worldwide public health problem. A variety of factors such as genetic lesions, environmental aspect and increasing adoption of unhealthy lifestyle are considered as crucial causes of cancer [1]. Among them, obesity is an important factor contributing to the occurrence and development of malignancies. According to the literature in 2005, 396 and 937 million people suffer from obese and overweight worldwide, respectively [2]. Epidemiological research reveals that obesity increases the risk of cancer with evidence that obese women have $50 \%$ higher incidence rate than normal weight women [3]. In the process of obesity, dysregulated circulating hormones and growth factors may play an important role in carcinogenesis [4]. Among them, aberrant adiponectin concentration is reported to be a vital link between obesity and cancer.

Adiponectin, firstly discovered by Scherer et al. in 1995 , is an adipokine predominantly produced by adipocytes with the monomeric subunit containing 244 amino-acids in human and circulates abundantly in plasma $[5,6]$. Three bioactive forms of adiponectin are produced 
after post-transcriptional process known as trimeric low molecular weight (90 kD, LMW), hexameric medium molecular weight (180 kD, MMW) and oligomeric high molecular weight ( $>400 \mathrm{kD}$, HMW) adiponectin. Among them, HMW-adiponectin is the dominant form in plasma and has the most biological activity than the other two isoforms [7]. Adiponectin mainly acts on two seven-transmembrane adiponectin receptors, AdipoR1 and AdipoR2. Besides, T-cadherin is also responsible for mediating the role of adiponectin in certain tissues $[8,9]$. Adiponectin exerts pleiotropic functions in human health such as anti-inflammation, anti-atherosclerosis, and anti-angiogenesis. It also has the properties of insulinsensitizing and balancing glucose and lipid metabolism in various cells [10]. A number of studies reveal that circulating adiponectin levels decrease in metabolic syndrome, whereas overexpression of it can counteract metabolic dysfunctions [10]. Besides, increased weight reduces the plasma adiponectin level and decreased weight upregulates circulating adiponectin level [11].

It was first reported that circulating adiponectin level was lower in patients with breast cancer in 2003 [12]. Since then, the most clinical studies have indicated that hypoadiponectinemia is associated with risk of various cancers including prostate, endometrial, and colorectal cancers [13-16]. In addition, adiponectin has antiproliferative and pro-apoptotic effects on cultured cancer cell lines $[17,18]$. These results suggest that adiponectin might be an important regulator in carcinogenesis and progression of cancers. However, unchanged or increased circulating adiponectin levels in pancreatic and hepatocellular carcinoma are also reported [19, 20]. Therefore, understanding the exact role of adiponectin in cancer may offer a novel target in tumor diagnosis and therapeutic strategy. In order to gain a more explicit and evidence-based conclusion on the association between circulating adiponectin levels and carcinogenesis, we conducted a comprehensive meta-analysis of current available studies.

\section{RESULTS}

\section{Literature selection}

The initial comprehensive search yielded 1486 articles, of which 235 articles were excluded for duplication. Then 997 studies were ruled out because of apparent irrelevance after reading titles and/or abstracts.

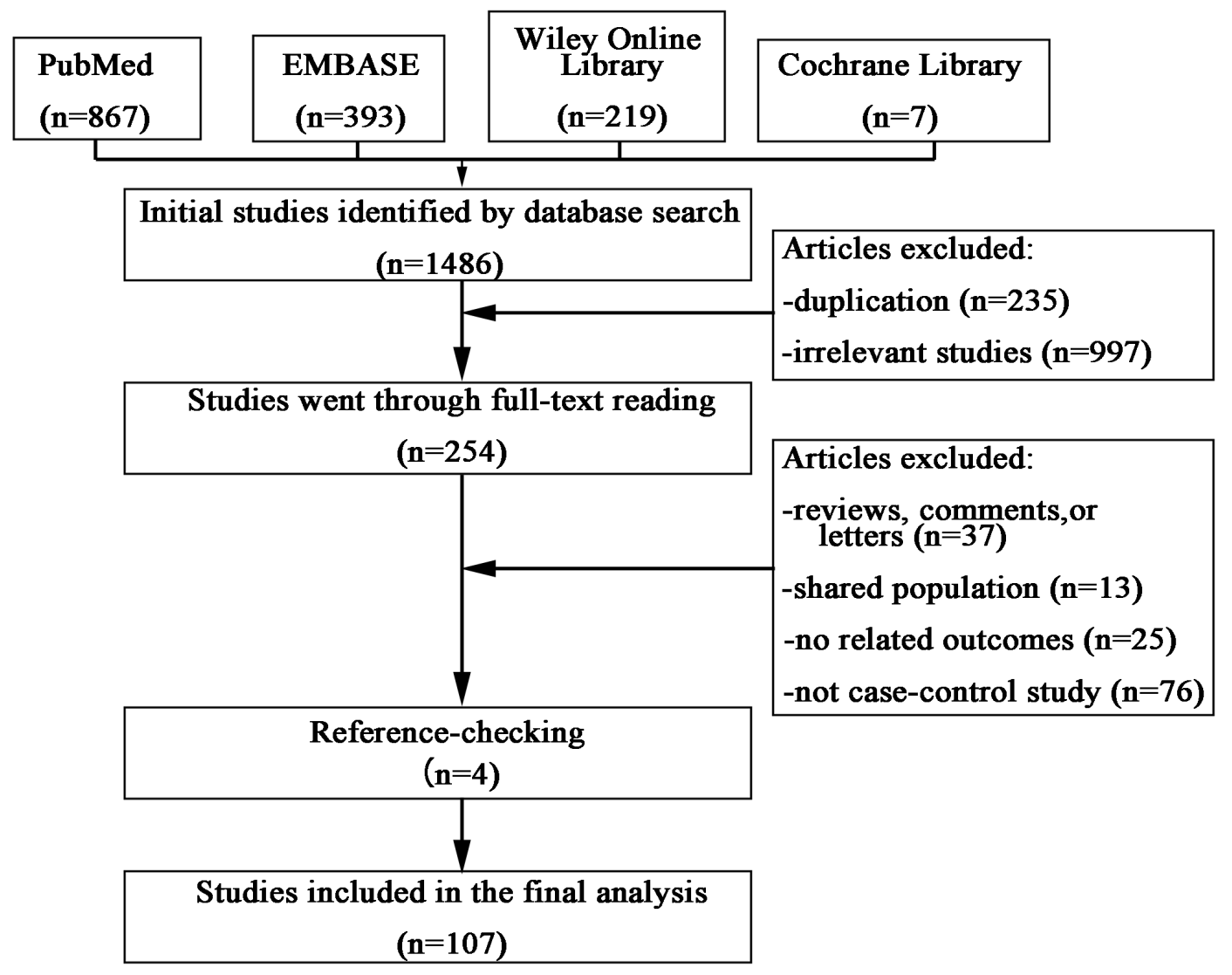

Figure 1: Flow diagram of the included studies. 
Table 1: Characteristics of all the included studies in the meta-analysis.

\begin{tabular}{|c|c|c|c|c|c|c|c|c|c|c|c|}
\hline Author & Year & Type & Country & Ethnicity & Sample & $\begin{array}{|ll|}\begin{array}{l}\text { Mean } \\
\text { (Case/ age } \\
\text { control) }\end{array} \\
\end{array}$ & \begin{tabular}{|l|} 
Number \\
(Case/ \\
control)
\end{tabular} & Study design & $\begin{array}{l}\text { Assay } \\
\text { method }\end{array}$ & Assay source & $\begin{array}{l}\text { Study } \\
\text { quality }\end{array}$ \\
\hline Petridou et al. & 2006 & Acute leukemia & $\begin{array}{l}\text { Greece/ } \\
\text { USA }\end{array}$ & Caucasian & Serum & NR & $201 / 201$ & Case-control & RIA & $\begin{array}{l}\text { Beth Israsel } \\
\text { Deaconess } \\
\text { Medical Center } \\
\end{array}$ & 8 \\
\hline Moschovi et al. & 2010 & Acute leukemia & Greece & Caucasian & Plasma & $4.3 / 5.2$ & $9 / 9$ & $\begin{array}{l}\text { Prospective } \\
\text { case-control }\end{array}$ & Other & Linco Research & 7 \\
\hline Aref et al. & 2013 & Acute leukemia & Egypt & African & Serum & $42.8 / 49.1$ & $80 / 20$ & Case-control & Elisa & R\&D Systems & 5 \\
\hline Miyoshi et al. & 2003 & Breast cancer & Japan & Asian & Serum & $54.0 / 52.8$ & $102 / 100$ & Case-control & Elisa & NR & 7 \\
\hline Mantzoros et al. & 2004 & Breast cancer & Greece & Caucasian & Serum & NR & $174 / 167$ & Case-control & RIA & \begin{tabular}{|l|l|} 
Beth Israsel \\
Deaconess \\
Medical Center \\
\end{tabular} & 8 \\
\hline Chen et al. & 2006 & Breast cancer & Taiwan & Asian & Serum & $49.9 / 48.9$ & $100 / 100$ & Case-control & RIA & Linco Research & 7 \\
\hline Korner et al. & 2007 & Breast cancer & Greece & Caucasian & Serum & $62.5 / 55.6$ & $74 / 76$ & Case-control & RIA & $\begin{array}{l}\text { ALPCO } \\
\text { Diagnostics }\end{array}$ & 7 \\
\hline Kang et al. & 2007 & Breast cancer & Korea & Asian & Serum & $47.4 / 47.8$ & $41 / 43$ & Case-control & Elisa & AdipoGen & 7 \\
\hline Hou et al. & 2007 & Breast cancer & China & Asian & Serum & $48 / 49$ & $80 / 50$ & Case-control & Elisa & R\&D Systems & 6 \\
\hline Tworoger et al. & 2007 & Breast cancer & USA & Caucasian & Blood & $57.1 / 58.1$ & $1166 / 1575$ & $\begin{array}{l}\text { Nested case- } \\
\text { control }\end{array}$ & RIA & Linco Research & 7 \\
\hline Tworoger et al. & 2007 & Breast cancer & USA & Caucasian & Blood & $45.4 / 45.1$ & $311 / 621$ & $\begin{array}{l}\text { Nested case- } \\
\text { control }\end{array}$ & RIA & Linco Research & 7 \\
\hline Hancke et al. & 2010 & Breast cancer & Switzerland & Caucasian & Serum & $59.5 / 49.0$ & $159 / 41$ & Case-control & Elisa & $\begin{array}{l}\text { BioVendor } \\
\text { Laboratory } \\
\text { Medicine }\end{array}$ & 6 \\
\hline Cust et al. & 2009 & Breast cancer & Sweden & Caucasian & Plasma & $52.5 / \mathrm{NR}$ & $561 / 561$ & Case-control & RIA & Linco Research & 7 \\
\hline Shahar et al. & 2010 & Breast cancer & Malaysia & Asian & Serum & $47.3 / 46.2$ & $70 / 138$ & Case-control & Elisa & Linco Research & 7 \\
\hline Dalamaga et al. & 2011 & Breast cancer & Greece & Caucasian & Serum & $61.5 / 62.8$ & $102 / 102$ & Case-control & Elisa & Avibion & 7 \\
\hline Al Khaldi et al. & 2011 & Breast cancer & Kuwait & Asian & Plasma & $49 / 60$ & $60 / 68$ & Case-control & Elisa & Linco Research & 7 \\
\hline Touvier et al. & 2013 & Breast cancer & France & Caucasian & Plasma & $49.2 / 51.5$ & $218 / 436$ & \begin{tabular}{|l|l|}
$\begin{array}{l}\text { Nested } \\
\text { control }\end{array}$ \\
\end{tabular} & Elisa & R\&D Systems & 9 \\
\hline Gulcelik et al. & 2012 & Breast cancer & Turkey & Asian & Serum & $51.4 / 52.4$ & $83 / 40$ & Case-control & Elisa & \begin{tabular}{|l|} 
B-Bridge \\
International Inc. \\
\end{tabular} & 7 \\
\hline Al Awadhi et al. & 2012 & Breast cancer & Kuwait & Asian & Plasma & $50.3 / 50.7$ & $144 / 77$ & Case-control & Elisa & Linco Research & 7 \\
\hline Alokail et al. & 2013 & Breast cancer & \begin{tabular}{|l|} 
Saudi \\
Arabia \\
\end{tabular} & Asian & Serum & $46.4 / 43.1$ & $56 / 53$ & Case-control & Other & \begin{tabular}{|l|l} 
Luminex \\
Corporation \\
\end{tabular} & 7 \\
\hline $\begin{array}{l}\text { Ollberding et } \\
\text { al. }\end{array}$ & 2013 & Breast cancer & USA & Caucasian & Serum & $67.8 / 67.8$ & $706 / 706$ & \begin{tabular}{|l|l|}
$\begin{array}{l}\text { Nested } \\
\text { control }\end{array}$ & case- \\
\end{tabular} & Elisa & R\&D Systems & 8 \\
\hline Gross et al. & 2013 & Breast cancer & USA & Caucasian & Plasma & $62.6 / 62.5$ & $272 / 272$ & Case-control & Elisa & \begin{tabular}{|l} 
ALPCO \\
Diagnostics \\
\end{tabular} & 7 \\
\hline Minatoya et al. & 2014 & Breast cancer & Japan & Asian & Serum & NR & $66 / 66$ & Case-control & Other & SRL & 7 \\
\hline Gulcelik et al. & 2012 & Colon cancer & Turkey & Asian & Serum & $52.1 / 52.4$ & $27 / 40$ & Case-control & Elisa & $\begin{array}{l}\text { B-Bridge } \\
\text { International Inc. }\end{array}$ & 7 \\
\hline Otake et al. & 2005 & Colorectal adenoma & Japan & Asian & Plasma & $59.0 / 58.0$ & $51 / 52$ & Case-control & Elisa & $\begin{array}{l}\text { Otsuka } \\
\text { Pharmaceutical } \\
\end{array}$ & 8 \\
\hline Fukumoto et al. & 2008 & Colorectal adenoma & Japan & Asian & Plasma & NR & $656 / 648$ & Case-control & Elisa & $\begin{array}{l}\text { Otsuka } \\
\text { Pharmaceutical }\end{array}$ & 7 \\
\hline Kumor et al. & 2009 & Colorectal adenoma & Poland & Caucasian & Serum & $62.4 / 60.1$ & $37 / 25$ & Case-control & Elisa & R\&D Systems & 7 \\
\hline Erarslan et al. & 2009 & Colorectal adenoma & Turkey & Asian & Plasma & $63.0 / 59.0$ & $31 / 50$ & Case-control & Elisa & RayBio & 8 \\
\hline Nakajima et al. & 2010 & Colorectal adenoma & Japan & Asian & Plasma & $66.8 / 66.7$ & $72 / 72$ & Case-control & Elisa & $\begin{array}{l}\text { Otsuka } \\
\text { Pharmaceutical }\end{array}$ & 7 \\
\hline Otake et al. & 2010 & Colorectal adenoma & Japan & Asian & Plasma & $65.1 / 67.9$ & $47 / 26$ & Case-control & Elisa & $\begin{array}{l}\text { Otsuka } \\
\text { Pharmaceutical }\end{array}$ & 7 \\
\hline Yamaji et al. & 2010 & Colorectal adenoma & Japan & Asian & Plasma & NR & $778 / 735$ & Case-control & Elisa & Sekisui Medical & 6 \\
\hline Danese et al. & 2013 & Colorectal adenoma & Italy & Caucasian & Serum & $63.0 / 59.5$ & $40 / 40$ & Case-control & Elisa & Mediagnost & 7 \\
\hline Wei et al. & 2005 & Colorectal cancer & USA & Caucasian & Plasma & $66.6 / 66.5$ & $179 / 356$ & $\begin{array}{l}\text { Nested case- } \\
\text { control }\end{array}$ & RIA & Linco Research & 8 \\
\hline Stocks et al. & 2008 & Colorectal cancer & Sweden & Caucasian & Plasma & $59.7 / \mathrm{NR}$ & $306 / 595$ & \begin{tabular}{|l|}
$\begin{array}{l}\text { Nested } \\
\text { control }\end{array}$ \\
\end{tabular} & Elisa & R\&D Systems & 6 \\
\hline Guadagni et al. & 2009 & Colorectal cancer & Italy & Caucasian & Serum & $63.0 / 59.0$ & $90 / 30$ & Case-control & Elisa & $\begin{array}{l}\text { BioVendor } \\
\text { Laboratory } \\
\text { Medicine } \\
\end{array}$ & 8 \\
\hline Kumor et al. & 2009 & Colorectal cancer & Poland & Caucasian & Serum & $58.6 / 60.1$ & $36 / 25$ & Case-control & Elisa & R\&D Systems & 7 \\
\hline Erarslan et al. & 2009 & Colorectal cancer & Turkey & Asian & Plasma & $57.0 / 59.0$ & $23 / 50$ & Case-control & Elisa & RayBio & 8 \\
\hline Nakajima et al. & 2010 & Colorectal cancer & Japan & Asian & Plasma & $63.7 / 63.5$ & $115 / 115$ & Case-control & Elisa & $\begin{array}{l}\text { Otsuka } \\
\text { Pharmaceutical }\end{array}$ & 7 \\
\hline Otake et al. & 2010 & Colorectal cancer & Japan & Asian & Plasma & $66.7 / 67.9$ & $51 / 26$ & Case-control & Elisa & $\begin{array}{l}\text { Otsuka } \\
\text { Pharmaceutical }\end{array}$ & 7 \\
\hline Kemik et al & 2010 & Colorectal cancer & Turkey & Asian & Serum & $43.5 / 40.4$ & $126 / 38$ & Case-control & RIA & Linco Research & 7 \\
\hline Gonullu et al. & 2010 & Colorectal cancer & Turkey & Asian & Serum & $56.6 / 51.0$ & $36 / 37$ & Case-control & Elisa & BioSource & 8 \\
\hline Catalan et al. & 2011 & Colorectal cancer & Spain & Caucasian & Plasma & $66.0 / 44.0$ & $11 / 18$ & Case-control & Elisa & R\&D Systems & 8 \\
\hline
\end{tabular}




\begin{tabular}{|c|c|c|c|c|c|c|c|c|c|c|c|}
\hline Chen et al. & 2012 & Colorectal cancer & China & Asian & Plasma & $61.9 / 58.3$ & $165 / 102$ & Case-control & Elisa & $\begin{array}{l}\text { Adlitteram } \\
\text { Diagnostic } \\
\text { Laboratories. Inc. }\end{array}$ & 7 \\
\hline Touvier et al. & 2012 & Colorectal cancer & France & Caucasian & Plasma & $51.8 / 52.1$ & $50 / 100$ & \begin{tabular}{|l|}
$\begin{array}{l}\text { Nested case- } \\
\text { control }\end{array}$ \\
\end{tabular} & Elisa & R\&D Systems & 9 \\
\hline $\begin{array}{l}\text { Aleksandrova } \\
\text { et al. }\end{array}$ & 2012 & Colorectal cancer & Germany & Caucasian & Serum & $58.3 / 58.3$ & $1206 / 1206$ & Case-control & Elisa & $\begin{array}{l}\text { ALPCO } \\
\text { Diagnostics }\end{array}$ & 9 \\
\hline Song et al. & 2013 & Colorectal cancer & USA & Caucasian & Plasma & $61.9 / 61.9$ & $616 / 1205$ & Case-control & Elisa & $\begin{array}{l}\text { ALPCO } \\
\text { Diagnostics }\end{array}$ & 9 \\
\hline Cust et al. & 2007 & \begin{tabular}{|l}
$\begin{array}{l}\text { Endometrical } \\
\text { carcinoma }\end{array}$ \\
\end{tabular} & UK & Caucasian & Plasma & $56.9 / 56.9$ & $284 / 548$ & \begin{tabular}{|l|l|}
$\begin{array}{l}\text { Nested } \\
\text { control }\end{array}$ & case- \\
\end{tabular} & Elisa & R\&D Systems & 8 \\
\hline Soliman et al. & 2006 & $\begin{array}{l}\text { Endometrical } \\
\text { carcinoma }\end{array}$ & USA & Caucasian & Serum & $66.6 / 61.2$ & $117 / 238$ & Case-control & Elisa & R\&D Systems & 5 \\
\hline Ashizawa et al. & 2010 & \begin{tabular}{|l|}
$\begin{array}{l}\text { Endometrical } \\
\text { carcinoma }\end{array}$ \\
\end{tabular} & Japan & Asian & Serum & $59.9 / 57.5$ & $146 / 150$ & Case-control & RIA & Linco Research & 8 \\
\hline Dossus et al. & 2013 & $\begin{array}{l}\text { Endometrical } \\
\text { carcinoma }\end{array}$ & Germany & Caucasian & Serum & $57.7 / 57.7$ & $233 / 446$ & Case-control & Elisa & R\&D Systems & 8 \\
\hline $\begin{array}{l}\text { Friedenreich } \\
\text { et al. }\end{array}$ & 2012 & $\begin{array}{l}\text { Endometrical } \\
\text { carcinoma }\end{array}$ & USA & Caucasian & Serum & $59 / 59$ & $514 / 962$ & Case-control & Elisa & $\begin{array}{l}\text { ALPCO } \\
\text { Diagnostics }\end{array}$ & 9 \\
\hline Luhn et al. & 2013 & $\begin{array}{l}\text { Endometrical } \\
\text { carcinoma }\end{array}$ & USA & Caucasian & Serum & NR & $167 / 327$ & \begin{tabular}{|l|l|}
$\begin{array}{l}\text { Nested } \\
\text { control }\end{array}$ & case- \\
\end{tabular} & RIA & Linco Research & 8 \\
\hline Erdogan et al. & 2013 & $\begin{array}{l}\text { Endometrical } \\
\text { carcinoma }\end{array}$ & Turkey & Asian & Serum & $56.6 / 49.7$ & $60 / 70$ & Case-control & Elisa & eBioscience & 6 \\
\hline Ma et al. & 2013 & $\begin{array}{l}\text { Endometrical } \\
\text { carcinoma }\end{array}$ & China & Asian & Serum & $53.2 / 53.3$ & $206 / 310$ & Case-control & Elisa & $\begin{array}{l}\text { Bender } \\
\text { MedSystems }\end{array}$ & 9 \\
\hline Dallal et al. & 2013 & \begin{tabular}{|l}
$\begin{array}{l}\text { Endometrical } \\
\text { carcinoma }\end{array}$ \\
\end{tabular} & USA & Caucasian & Serum & $67.4 / 67.5$ & $62 / 124$ & \begin{tabular}{|l|l|}
$\begin{array}{l}\text { Nested } \\
\text { control }\end{array}$ & case- \\
\end{tabular} & Elisa & Millipore & 8 \\
\hline Mihu et al. & 2013 & $\begin{array}{l}\text { Endometrical } \\
\text { carcinoma }\end{array}$ & Romania & Caucasian & Serum & $60.2 / 58.5$ & $44 / 44$ & Case-control & Elisa & R\&D Systems & 6 \\
\hline Ohbuchi et al. & 2014 & $\begin{array}{l}\text { Endometrical } \\
\text { carcinoma }\end{array}$ & Japan & Asian & Serum & $61.2 / 58.1$ & $43 / 62$ & Case-control & Elisa & Daiichi Co. Ltd. & 8 \\
\hline Diao et al. & 2009 & Esophageal cancer & China & Asian & Plasma & $58.0 / 49.0$ & $43 / 33$ & Case-control & Elisa & \begin{tabular}{|l|} 
Adlitteram \\
Diagnostic \\
Laboratories. Inc.
\end{tabular} & 6 \\
\hline Nakajima et al. & 2010 & Esophageal cancer & Japan & Asian & Blood & 63.6/63.6 & $117 / 117$ & Case-control & Elisa & $\begin{array}{l}\text { Otsuka } \\
\text { Pharmaceutical }\end{array}$ & 6 \\
\hline Yildirim et al. & 2009 & Esophageal cancer & Turkey & Asian & Serum & $64 / 61$ & $62 / 30$ & Case-control & Elisa & Avibion & 6 \\
\hline Ishikawa et al. & 2005 & Gastric cancer & Japan & Asian & Plasma & $64.2 / 59.3$ & $75 / 52$ & Case-control & Elisa & $\begin{array}{l}\text { Otsuka } \\
\text { Pharmaceutical }\end{array}$ & 6 \\
\hline Nakajima et al. & 2009 & Gastric cancer & Japan & Asian & Blood & 61.0/60.8 & $156 / 156$ & Case-control & Elisa & $\begin{array}{l}\text { Otsuka } \\
\text { Pharmaceutical }\end{array}$ & 8 \\
\hline Seker et al. & 2010 & Gastric cancer & Turkey & Asian & Plasma & $60.0 / 38.6$ & $40 / 43$ & Case-control & Elisa & Linco Research & 5 \\
\hline $\begin{array}{l}\text { Diakowska et } \\
\text { al. }\end{array}$ & 2014 & $\begin{array}{l}\begin{array}{l}\text { Gastroesophageal } \\
\text { cancer }\end{array} \\
\end{array}$ & Poland & Caucasian & Serum & $60.0 / 58.0$ & $85 / 60$ & Case-control & Elisa & R\&D Systems & 7 \\
\hline Kotani et al. & 2009 & $\begin{array}{l}\text { Hepatacellular } \\
\text { carcinoma }\end{array}$ & Japan & Asian & Serum & $63.5 / 62.7$ & $59 / 334$ & \begin{tabular}{|l|l|}
$\begin{array}{l}\text { Nested } \\
\text { control }\end{array}$ & case- \\
\end{tabular} & Elisa & Daiichi Co. Ltd. & 8 \\
\hline Liu et al. & 2009 & \begin{tabular}{|l}
$\begin{array}{l}\text { Hepatacellular } \\
\text { carcinoma }\end{array}$ \\
\end{tabular} & \begin{tabular}{|l} 
Taiwan/ \\
China
\end{tabular} & Asian & Serum & $50.7 / 53.8$ & $120 / 116$ & Case-control & Elisa & \begin{tabular}{|l|} 
B-Bridge \\
International Inc. \\
\end{tabular} & 5 \\
\hline Sumie et al. & 2011 & $\begin{array}{l}\text { Hepatacellular } \\
\text { carcinoma }\end{array}$ & Japan & Asian & Serum & $67.4 / 61.2$ & 97/97 & Case-control & Elisa & $\begin{array}{l}\text { EikenChenical } \\
\text { Co. Ltd. }\end{array}$ & 7 \\
\hline Sadik et al & 2012 & $\begin{array}{l}\text { Hepatacellular } \\
\text { carcinoma }\end{array}$ & Egypt & African & Serum & $58.9 / 55.7$ & $69 / 121$ & Case-control & Elisa & Assaypro & 7 \\
\hline Chen et al. & 2012 & $\begin{array}{l}\text { Hepatacellular } \\
\text { carcinoma }\end{array}$ & $\begin{array}{l}\text { Taiwan/ } \\
\text { China }\end{array}$ & Asian & Serum & $52.4 / 52.2$ & $65 / 165$ & Case-control & RIA & Linco Research & 6 \\
\hline Khattab et al. & 2012 & \begin{tabular}{|l}
$\begin{array}{l}\text { Hepatacellular } \\
\text { carcinoma }\end{array}$ \\
\end{tabular} & Egypt & African & Plasma & $43.9 / 42.9$ & $147 / 320$ & Case-control & Other & Linco Research & 5 \\
\hline Chen et al. & 2014 & $\begin{array}{l}\text { Hepatacellular } \\
\text { carcinoma }\end{array}$ & $\begin{array}{l}\text { Taiwan/ } \\
\text { China }\end{array}$ & Asian & Plasma & NR & $185 / 373$ & $\begin{array}{l}\text { Nested case- } \\
\text { control }\end{array}$ & Elisa & $\begin{array}{l}\text { B-Bridge } \\
\text { International Inc. }\end{array}$ & 8 \\
\hline Petridou et al. & 2010 & Hodgkin lymphoma & Greece & Caucasian & Serum & $11.5 / 11.2$ & $75 / 75$ & Case-control & RIA & Linco Research & 7 \\
\hline Jamieson et al. & 2004 & Lung cancer & UK & Caucasian & Serum & $64.0 / 65.0$ & $20 / 13$ & Case-control & RIA & Linco Research & 7 \\
\hline $\begin{array}{l}\text { Karapanagiotou } \\
\text { et al. }\end{array}$ & 2008 & Lung cancer & Greece & Caucasian & Serum & $64.2 / 55.5$ & $101 / 51$ & Case-control & Elisa & BioVendor & 6 \\
\hline Petridou et al. & 2007 & Lung cancer & Greece & Caucasian & Serum & NR & $85 / 170$ & Case-control & RIA & $\begin{array}{l}\text { Beth Israsel } \\
\text { Deaconess } \\
\text { Medical Center }\end{array}$ & 8 \\
\hline Gulen et al. & 2012 & Lung cancer & Turkey & Asian & Serum & $65.6 / 63.5$ & $63 / 25$ & Case-control & Elisa & BioVendor & 7 \\
\hline Kerenidi et al. & 2013 & Lung cancer & Greece & Caucasian & Serum & $62.9 / \mathrm{NR}$ & $80 / 40$ & Case-control & Elisa & Linco Research & 7 \\
\hline $\begin{array}{l}\text { Antoniadis et } \\
\text { al. }\end{array}$ & 2011 & Melanoma & $\begin{array}{l}\text { Greece/ } \\
\text { Canada }\end{array}$ & Caucasian & Serum & $52.7 / 53.3$ & $55 / 165$ & Case-control & RIA & \begin{tabular}{|l|} 
Beth Israsel \\
Deaconess \\
Medical Center \\
\end{tabular} & 8 \\
\hline Dalamaga et al. & 2009 & Multiple myeloma & $\begin{array}{l}\text { Greece/ } \\
\text { Canada }\end{array}$ & Caucasian & Serum & NR & $73 / 73$ & Case-control & Elisa & Avibion & 8 \\
\hline
\end{tabular}




\begin{tabular}{|c|c|c|c|c|c|c|c|c|c|c|c|}
\hline Hofmann et al. & 2012 & Multiple myeloma & USA & Caucasian & Plasma & NR & $174 / 348$ & Case-control & Elisa & R\&D Systems & 7 \\
\hline Pamuk et al. & 2006 & \begin{tabular}{|l|}
$\begin{array}{l}\text { Non-Hodgkin's } \\
\text { lymphoma }\end{array}$ \\
\end{tabular} & Turkey & Asian & Serum & $63.2 / 58.5$ & $28 / 17$ & Case-control & Elisa & OtsukaCo.Ltd & 5 \\
\hline Petridou et al. & 2009 & $\begin{array}{l}\text { Non-Hodgkin's } \\
\text { lymphoma } \\
\end{array}$ & Greece & Caucasian & Serum & $8.8 / 8.8$ & $121 / 121$ & Case-control & RIA & NR & 7 \\
\hline Conroy et al. & 2013 & $\begin{array}{l}\text { Non-Hodgkin's } \\
\text { lymphoma }\end{array}$ & USA & Caucasian & Plasma & $70.0 / 70.0$ & $272 / 541$ & $\begin{array}{|ll|}\begin{array}{l}\text { Nested } \\
\text { control }\end{array} & \text { case- } \\
\end{array}$ & Elisa & R\&D Systems & 7 \\
\hline Chang et al. & 2007 & Pancreatic cancer & \begin{tabular}{|l} 
Taiwan/ \\
China \\
\end{tabular} & Asian & Serum & $64.6 / 49.5$ & $72 / 290$ & Case-control & Elisa & R\&D Systems & 8 \\
\hline Dalamaga et al. & 2009 & Pancreatic cancer & Greece & Caucasian & Serum & 69.0/70.1 & $81 / 81$ & Case-control & RIA & Linco Research & 7 \\
\hline Solomon et al. & 2008 & Pancreatic cancer & USA & Caucasian & Serum & $58.0 / 58.0$ & $311 / 510$ & Case-control & Elisa & Millipore & 8 \\
\hline Krechler et al. & 2011 & Pancreatic cancer & \begin{tabular}{|l|} 
Czech \\
Republic \\
\end{tabular} & Caucasian & Plasma & $51.9 / 64.5$ & $64 / 64$ & Case-control & RIA & DRG Inc. & 8 \\
\hline Grote et al. & 2012 & Pancreatic cancer & Germany & Caucasian & Serum & $58.0 / 60.0$ & $452 / 452$ & $\begin{array}{l}\text { Nested case- } \\
\text { control }\end{array}$ & Other & R\&D Systems & 8 \\
\hline Bao et al. & 2013 & Pancreatic cancer & USA & Caucasian & Plasma & NR & $468 / 1080$ & $\begin{array}{|ll|}\begin{array}{l}\text { Nested } \\
\text { control }\end{array} & \text { case- } \\
\end{array}$ & Elisa & \begin{tabular}{|l|} 
ALPCO \\
Diagnostics
\end{tabular} & 8 \\
\hline Goktas et al. & 2005 & Prostate cancer & Turkey & Asian & Plasma & $65.8 / 62.2$ & $30 / 36$ & Case-control & RIA & Linco Research & 8 \\
\hline Goktas et al. & 2005 & Prostate cancer & Turkey & Asian & Plasma & $65.8 / 65.0$ & $30 / 41$ & Case-control & RIA & Linco Research & 8 \\
\hline $\begin{array}{l}\text { Baillargeon et } \\
\text { al. }\end{array}$ & 2006 & Prostate cancer & USA & Caucasian & Serum & $63.5 / 63.2$ & $125 / 125$ & $\begin{array}{|ll|}\text { Nested } & \text { case- } \\
\text { control }\end{array}$ & Other & Luminex & 7 \\
\hline $\begin{array}{l}\text { Michalakis et } \\
\text { al. } \\
\end{array}$ & 2007 & Prostate cancer & Greece & Caucasian & Serum & 74.0/64.0 & $75 / 150$ & Case-control & RIA & Linco Research & 5 \\
\hline $\begin{array}{l}\text { Michalakis et } \\
\text { al. }\end{array}$ & 2007 & Prostate cancer & Greece & Caucasian & Serum & 74.0/70.0 & $75 / 75$ & Case-control & RIA & Linco Research & 5 \\
\hline Housa et al. & 2008 & Prostate cancer & \begin{tabular}{|l|} 
Czech \\
Republic
\end{tabular} & Caucasian & Serum & $63.6 / 70.5$ & $43 / 25$ & Case-control & RIA & Linco Research & 5 \\
\hline Grosman et al. & 2010 & Prostate cancer & Argentina & Caucasian & Serum & NR & $25 / 25$ & Case-control & RIA & Linco Research & 7 \\
\hline Li et al. & 2010 & Prostate cancer & USA & Caucasian & Plasma & $59.0 / 58.6$ & $620 / 599$ & $\begin{array}{|ll|}\begin{array}{l}\text { Nested } \\
\text { control }\end{array} & \text { case- } \\
\end{array}$ & RIA & Linco Research & 7 \\
\hline Dhillon et al. & 2011 & Prostate cancer & USA & Caucasian & Plasma & $57.9 / 57.5$ & $1286 / 1267$ & $\begin{array}{|ll|}\begin{array}{l}\text { Nested } \\
\text { control }\end{array} & \text { case- } \\
\end{array}$ & RIA & Linco Research & 8 \\
\hline $\begin{array}{l}\text { Lopez Fontana } \\
\text { et al. }\end{array}$ & 2011 & Prostate cancer & Argentina & Caucasian & Serum & $63.8 / 64.9$ & $35 / 35$ & Case-control & Elisa & Linco Research & 6 \\
\hline Al Khaldi et al. & 2011 & Prostate cancer & Kuwait & Asian & Plasma & $59.0 / 60.0$ & $14 / 68$ & Case-control & Elisa & Linco Research & 7 \\
\hline Touvier et al. & 2013 & Prostate cancer & France & Caucasian & Plasma & $54.9 / 51.5$ & $156 / 1024$ & $\begin{array}{|ll|}\begin{array}{l}\text { Nested } \\
\text { control }\end{array} & \text { case- } \\
\end{array}$ & Elisa & R\&D Systems & 9 \\
\hline Tewari et al. & 2013 & Prostate cancer & India & Asian & Blood & $66.5 / 65.7$ & $95 / 95$ & Case-control & Other & NR & 5 \\
\hline $\begin{array}{l}\text { Spyridopoulos } \\
\text { et al. }\end{array}$ & 2012 & Renal cancer & Greece & Caucasian & Serum & $61.5 / 60.7$ & $60 / 236$ & Case-control & RIA & \begin{tabular}{|l|l|} 
Beth Israsel \\
Deaconess \\
Medical Center \\
\end{tabular} & 8 \\
\hline Liao et al. & 2013 & Renal cancer & $\begin{array}{l}\text { Finland/ } \\
\text { USA }\end{array}$ & Caucasian & Serum & $57 / 57$ & $273 / 273$ & $\begin{array}{|ll|}\text { Nested case- } \\
\text { control }\end{array}$ & Elisa & Millipore & 9 \\
\hline Liao et al. & 2013 & Renal cancer & \begin{tabular}{|l} 
Canada/ \\
USA
\end{tabular} & Caucasian & Serum & NR & 768/917 & Case-control & Elisa & Millipore & 9 \\
\hline Mitsiades et al. & 2011 & Thyroid cancer & USA & Caucasian & Serum & $51.2 / 55.4$ & $175 / 107$ & Case-control & RIA & \begin{tabular}{|l|} 
Beth Israsel \\
Deaconess \\
Medical Center
\end{tabular} & 5 \\
\hline Guo et al. & 2013 & Tongue cancer & China & Asian & Serum & $57.2 / 52.7$ & $59 / 50$ & Case-control & Elisa & Adipobiotech & 8 \\
\hline
\end{tabular}

Abbreviations: NR, not reported; Elisa, enzyme-linked immunosorbent assay; RIA, radioimmunoassay.

The remaining 254 studies were included for full-text reading, of which 151 studies were removed for one of the following reasons: (i) reviews, comments or letters ( $\mathrm{n}=37$ ); (ii) shared population ( $\mathrm{n}=13$ ); (iii) no report of adiponectin levels and/or SDs for both patients and controls or there was not enough information to calculate them $(\mathrm{n}=25)$; (iv) not case-control study $(\mathrm{n}=76) .4$ additional studies were included from checking the references list. Finally, 107 studies met the inclusion criteria and were used for further analysis $[12,13,15,16$, 20-112]. The flow diagram of this selection process was showed in Figure 1.

\section{Study characteristics}

Among the 107 studies, a total of 25,675 controls and 19,319 cases were enrolled until August, 2015. Geographic regions were various, among which 46 studies from Asia, 39 studies from Europe, 19 studies from America, and 3 studies from Africa. 16 types of malignancies were investigated in this meta-analysis, with digestive system cancers accounting for the largest percentage (43 studies); other types included: breast cancer (20 studies), prostate cancer (13 studies), endometrial carcinoma (11 studies), lung cancer (5 studies), renal cancer (3 studies), acute leukemia (3 studies), non-Hodgkin's lymphoma (3 studies), Hodgkin's lymphoma (1 study), multiple myeloma (2 studies), 


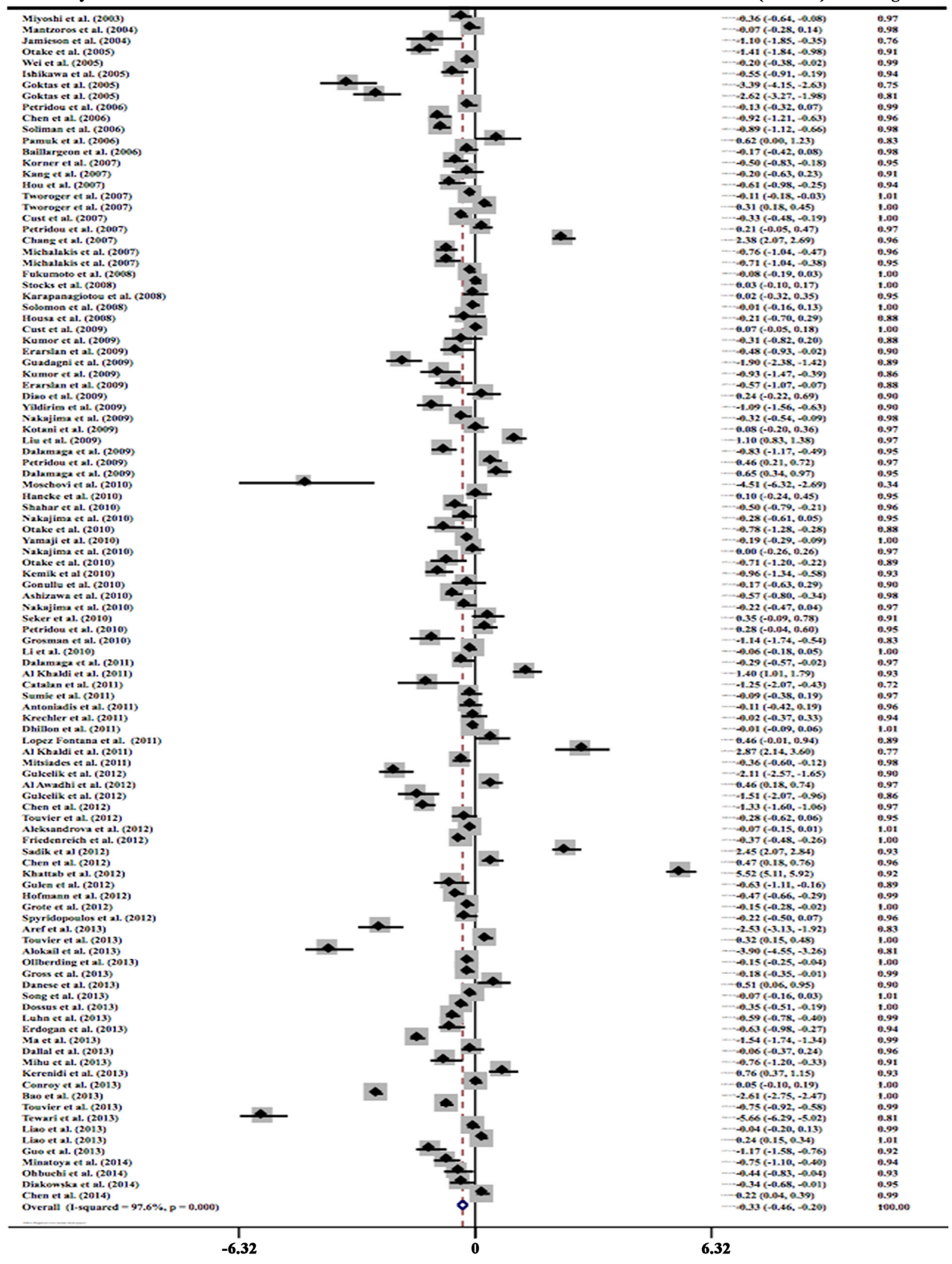

Figure 2: Forest plot of studies in circulating total adiponectin and cancer risk. The combined SMD and $95 \%$ CIs were calculated through a random-effect model. 
Table 2: Subgroup analysis of the relationships between circulating adiponectin levels and study characteristics.

\begin{tabular}{|c|c|c|c|c|c|}
\hline Characteristics & \begin{tabular}{|l|}
$\begin{array}{l}\text { Number of } \\
\text { studies }\end{array}$ \\
\end{tabular} & $\begin{array}{l}\text { Number } \\
\text { (Case/control) }\end{array}$ & SMD & $95 \%$ CI & Heterogeneity (I2) \\
\hline \multicolumn{6}{|l|}{ Ethnicity } \\
\hline Caucasian & 58 & $14178 / 19758$ & -0.269 & -0.400 to -0.138 & $96.8 \%$ \\
\hline Asian & 46 & $4845 / 5456$ & -0.555 & -0.812 to -0.298 & $97.1 \%$ \\
\hline African & 3 & $296 / 461$ & 1.821 & -2.201 to 5.843 & $99.6 \%$ \\
\hline \multicolumn{6}{|l|}{ Cancer Types } \\
\hline Acute leukemia & 3 & $290 / 230$ & -2.236 & -4.418 to -0.054 & $97.3 \%$ \\
\hline Multiple myeloma & 2 & $247 / 421$ & -0.621 & -0.966 to -0.276 & $69.7 \%$ \\
\hline Breast cancer & 20 & $4545 / 5292$ & -0.334 & -0.543 to -0.126 & $95.5 \%$ \\
\hline Colorectal cancers & 23 & $4749 / 5591$ & -0.496 & -0.653 to -0.339 & $91.3 \%$ \\
\hline Endometrial cancer & 11 & $1876 / 3281$ & -0.594 & -0.825 to -0.363 & $92.8 \%$ \\
\hline Prostate cancer & 13 & $2609 / 3565$ & -0.892 & -1.345 to -0.438 & $97.9 \%$ \\
\hline Thyroid cancer & 1 & $175 / 107$ & -0.358 & -0.601 to -0.116 & NA \\
\hline Tongue cancer & 1 & $59 / 50$ & -1.172 & -1.580 to -0.764 & NA \\
\hline Hepatocellular cancer & 7 & $742 / 1526$ & 1.385 & 0.240 to 2.530 & $99.2 \%$ \\
\hline Gastroesophageal cancer & 7 & $578 / 491$ & -0.278 & -0.553 to -0.004 & $78.1 \%$ \\
\hline Hodgkin lymphoma & 1 & $75 / 75$ & 0.28 & -0.041 to 0.602 & NA \\
\hline Non-Hodgkin lymphoma & 3 & $421 / 679$ & 0.316 & -0.048 to 0.68 & $79.7 \%$ \\
\hline Lung cancer & 5 & $349 / 299$ & -0.085 & -0.58 to 0.409 & $87.1 \%$ \\
\hline Melanoma & 1 & $55 / 165$ & -0.112 & -0.418 to 0.193 & NA \\
\hline Pancreatic cancer & 6 & $1448 / 2477$ & 0.037 & -1.207 to 1.281 & $99.6 \%$ \\
\hline Renal cancer & 3 & $1101 / 1426$ & 0.021 & -0.246 to 0.288 & $86.6 \%$ \\
\hline \multicolumn{6}{|l|}{ Study Design } \\
\hline Case-control study & 86 & $11965 / 14210$ & -0.346 & -0.505 to -0.188 & $97.2 \%$ \\
\hline Nested case-control study & 21 & $7354 / 11465$ & -0.290 & -0.553 to -0.026 & $98.5 \%$ \\
\hline \multicolumn{6}{|l|}{ Blood samples } \\
\hline Serum & 65 & 9171/11101 & -0.335 & -0.483 to -0.186 & $95.8 \%$ \\
\hline Plasma & 37 & $8303 / 12010$ & -0.238 & -0.497 to 0.022 & $98.6 \%$ \\
\hline NR & 5 & $1845 / 2564$ & -1.072 & -1.775 to -0.369 & $98.8 \%$ \\
\hline \multicolumn{6}{|l|}{ Assay methods } \\
\hline RIA & 29 & $6190 / 7587$ & -0.316 & -0.459 to -0.172 & $93.0 \%$ \\
\hline Elisa & 71 & $12179 / 16968$ & -0.266 & -0.426 to -0.106 & $97.4 \%$ \\
\hline Others & 7 & $950 / 1120$ & -1.305 & -3.113 to 0.502 & $99.5 \%$ \\
\hline \multicolumn{6}{|l|}{ Study size } \\
\hline$\geq 100$ patients & 48 & $16057 / 21437$ & -0.135 & -0.299 to -0.030 & $98.3 \%$ \\
\hline$<100$ patients & 59 & $3262 / 4238$ & -0.549 & -0.825 to -0.273 & $96.5 \%$ \\
\hline \multicolumn{6}{|l|}{ Study quality } \\
\hline$\geq 6$ & 96 & $16352 / 22425$ & -0.334 & -0.465 to -0.203 & $97.3 \%$ \\
\hline$<6$ & 11 & $2967 / 3250$ & -0.267 & -0.700 to 0.165 & $98.2 \%$ \\
\hline \multicolumn{6}{|l|}{ Patients' age (mean) } \\
\hline$\geq 60$ & $44^{*}$ & $4770 / 6414^{*}$ & -0.489 & -0.689 to -0.288 & $95.6 \%$ \\
\hline$<60$ & $47 *$ & 9782/12935* & -0.194 & -0.383 to -0.004 & $97.7 \%$ \\
\hline
\end{tabular}

Abbreviations: NA, not assessable. *There are 91 studies with 14,552 cases and 19,349 controls reported the mean age of cancer patients. 
Table 3: The pooled SMDs and $95 \%$ CIs of the included studies through sensitivity analysis.

\begin{tabular}{|c|c|c|}
\hline Study omitted & Estimate & $95 \% \mathrm{CI}$ \\
\hline Miyoshi et al. (2003) & -0.33362126 & -.46549249 to -.20175007 \\
\hline Jamieson et al. (2004) & -0.32790136 & -.45929646 to -.19650623 \\
\hline Mantzoros et al. (2004) & -0.3366529 & -.46877834 to -.20452745 \\
\hline Goktas et al. (2005) & -0.31018904 & -.44067159 to -.1797065 \\
\hline Goktas et al. (2005) & -0.31467217 & -.4453963 to -.18394804 \\
\hline Wei et al. (2005) & -0.33543056 & -.46779135 to -.20306975 \\
\hline Otake et al. (2005) & -0.32370359 & -.45491788 to -.19248928 \\
\hline Ishikawa et al. (2005) & -0.33179379 & -.4634814 to -.20010617 \\
\hline Petridou et al. (2006) & -0.33611172 & -.4683494 to -.20387407 \\
\hline Baillargeon et al. (2006) & -0.33559188 & -.46757615 to -.2036076 \\
\hline Chen et al. (2006) & -0.32800215 & -.45950019 to -.1965041 \\
\hline Pamuk et al. (2006) & -0.34167045 & -.47312284 to -.21021806 \\
\hline Soliman et al. (2006) & -0.32821506 & -.45972851 to -.19670163 \\
\hline Cust et al. (2007) & -0.33429027 & -.46701819 to -.20156233 \\
\hline Korner et al. (2007) & -0.33221245 & -.4639549 to -.20046999 \\
\hline Kang et al. (2007) & -0.33505732 & -.46672907 to -.20338558 \\
\hline Tworoger et al. (2007) & -0.33802846 & -.47386777 to -.20218913 \\
\hline Tworoger et al. (2007) & -0.3405844 & -.47277904 to -.20838977 \\
\hline Chang et al. (2007) & -0.35825887 & -.48626736 to -.2302504 \\
\hline Michalakis et al. (2007) & -0.32968622 & -.46133375 to -.19803868 \\
\hline Michalakis et al. (2007) & -0.33015183 & -.46179458 to -.19850905 \\
\hline Hou et al. (2007) & -0.33114624 & -.46280947 to -.19948301 \\
\hline Petridou et al. (2007) & -0.33918613 & -.47100937 to -.20736288 \\
\hline Fukumoto et al. (2008) & -0.33727011 & -.47093907 to -.20360115 \\
\hline Solomon et al. (2008) & -0.3375347 & -.47031215 to -.20475723 \\
\hline Housa et al. (2008) & -0.33494586 & -.46656513 to -.2033266 \\
\hline Karapanagiotou et al. (2008) & -0.337192 & -.46895465 to -.20542936 \\
\hline Stocks et al. (2008) & -0.33803195 & -.47080877 to -.20525511 \\
\hline Dalamaga et al. (2009) & -0.34321341 & -.47464448 to -.21178232 \\
\hline Dalamaga et al. (2009) & -0.32902971 & -.46060005 to -.19745934 \\
\hline Petridou et al. (2009) & -0.34161058 & -.47322133 to -.2099998 \\
\hline Kotani et al. (2009) & -0.33791459 & -.46976718 to -.20606196 \\
\hline
\end{tabular}




\begin{tabular}{|c|c|c|}
\hline Guadagni et al. (2009) & -0.31941918 & -.45032975 to -.18850861 \\
\hline Kumor et al. (2009) & -0.32856214 & -.46004361 to -.1970806 \\
\hline Erarslan et al. (2009) & -0.33168712 & -.46326634 to -.20010787 \\
\hline Kumor et al. (2009) & -0.3339898 & -.4655939 to -.2023856 \\
\hline Erarslan et al. (2009) & -0.33251002 & -.46413583 to -.20088424 \\
\hline Cust et al. (2009) & -0.33854863 & -.47171903 to -.20537826 \\
\hline Nakajima et al. (2009) & -0.33416247 & -.4662253 to -.20209965 \\
\hline Diao et al. (2009) & -0.33897933 & -.47058302 to -.2073756 \\
\hline Yildirim et al. (2009) & -0.3268407 & -.45826575 to -.19541568 \\
\hline Li et al. (2009) & -0.34737712 & -.47806501 to -.21668923 \\
\hline Moschovi et al. (2010) & -0.31926209 & -.45011383 to -.18841037 \\
\hline Hancke et al. (2010) & -0.33801222 & -.46974581 to -.20627865 \\
\hline Seker et al. (2010) & -0.34004903 & -.47163537 to -.2084627 \\
\hline Nakajima et al. (2010) & -0.33507797 & -.46703228 to -.20312366 \\
\hline Petridou et al. (2010) & -0.33972663 & -.47141987 to -.20803338 \\
\hline Grosman et al. (2010) & -0.32690996 & -.45831883 to -.19550107 \\
\hline Li et al. (2010) & -0.3373847 & -.47090244 to -.20386696 \\
\hline Nakajima et al. (2010) & -0.3372006 & -.46912611 to -.2052751 \\
\hline Otake et al. (2010) & -0.3304036 & -.46196187 to -.19884537 \\
\hline Kemik et al (2010) & -0.3278496 & -.45933568 to -.19636351 \\
\hline Gonullu et al. (2010) & -0.3353405 & -.46698609 to -.20369488 \\
\hline Nakajima et al. (2010) & -0.33436027 & -.46614832 to -.20257224 \\
\hline Ashizawa et al. (2010) & -0.33154425 & -.4634259 to -.19966258 \\
\hline Shahar et al. (2010) & -0.3222657 & -.4640207 to -.20043245 \\
\hline Otake et al. (2010) & -0.3297922 & -.46132797 to -.19825645 \\
\hline Yamaji et al. (2010) & -0.33636427 & -.47040036 to -.20232819 \\
\hline Antoniadis et al. (2011) & -0.3360277 & -.46786067 to -.2041948 \\
\hline Dhillon et al. (2011) & -0.33877328 & -.47420669 to -.20333987 \\
\hline Al Khaldi et al. (2011) & -0.3581396 & -.48865175 to -.22762746 \\
\hline Sumie et al. (2011) & -0.33623996 & -.46812296 to -.20435697 \\
\hline Catalan et al. (2011) & -0.3270525 & -.4584052 to -.19569978 \\
\hline Dalamaga et al. (2011) & -0.33432293 & -.46621501 to -.20243084 \\
\hline Al Khaldi et al. (2011) & -0.34966454 & -.48045498 to -.21887414 \\
\hline
\end{tabular}




\begin{tabular}{|c|c|c|}
\hline Krechler et al. (2011) & -0.33685401 & -.46860847 to -.20509957 \\
\hline Mitsiades et al. (2011) & -0.33370164 & -.46567562 to -.20172767 \\
\hline Lopez Fontana et al. (2011) & -0.3409504 & -.47248313 to -.20941767 \\
\hline Spyridopoulos et al. (2012) & -0.33505121 & -.46693206 to -.20317033 \\
\hline Hofmann et al. (2012) & -0.33265379 & -.46483427 to -.2004733 \\
\hline Gulen et al. (2012) & -0.33108562 & -.46266881 to -.1995024 \\
\hline Sadik et al (2012) & -0.35871589 & -.48782459 to -.2296071 \\
\hline Chen et al. (2012) & -0.32368076 & -.45458078 to -.1927807 \\
\hline Gulcelik et al. (2012) & -0.32346013 & -.45471603 to -.19220424 \\
\hline Aleksandrova et al. (2012) & -0.33816311 & -.47353563 to -.20279059 \\
\hline Friedenreich et al. (2012) & -0.33428073 & -.46782497 to -.20073651 \\
\hline Touvier et al. (2012) & -0.3405067 & -.47251758 to -.20849583 \\
\hline Gulcelik et al. (2012) & -0.31726849 & -.44793424 to -.18660273 \\
\hline Al Awadhi et al. (2012) & -0.34153 & -.47313255 to -.2099274 \\
\hline Grote et al. (2012) & 0.33630246 & -.46936187 to -.20324306 \\
\hline Chen et al. (2012) & -0.34161338 & -.47320184 to -.2100249 \\
\hline Khattab et al. (2012) & -0.38207525 & -.50227177 to -.2618787 \\
\hline Dossus et al. (2013) & -0.33401754 & -.46652448 to -.20151059 \\
\hline Bao et al. (2013) & -0.30136451 & -.41626969 to -.18645933 \\
\hline Guo et al. (2013) & -0.3258861 & -.45724642 to -.1945257 \\
\hline Touvier et al. (2013) & -0.33433828 & -.46610662 to -.2025699 \\
\hline Liao et al. (2013) & -0.33713764 & -.46957946 to -.20469585 \\
\hline Liao et al. (2013) & -0.3403554 & -.47350773 to -.20720309 \\
\hline Conroy et al. (2013) & -0.33808553 & -.47072488 to -.2054462 \\
\hline Touvier et al. (2013) & -0.3296572 & -.46145904 to -.19785538 \\
\hline Kerenidi et al. (2013) & -0.3439351 & -.4753255 to -.21254471 \\
\hline Danese et al. (2013) & -0.34142008 & -.47294763 to -.20989256 \\
\hline Song et al. (2013) & -0.33765575 & -.47181916 to -.20349233 \\
\hline Luhn et al. (2013) & -0.33139816 & -.46341154 to -.19938481 \\
\hline Ma et al. (2013) & -0.32076678 & -.45034227 to -.1911912 \\
\hline Dallal et al. (2013) & -0.33651593 & -.4683443 to -.20468754 \\
\hline Alokail et al. (2013) & -0.30377382 & -.43343174 to -.17411587 \\
\hline Ollberding et al. (2013) & -0.33671638 & -.47059336 to -.20283943 \\
\hline
\end{tabular}




\begin{tabular}{|l|l|l|}
\hline Gross et al. (2013) & -0.33571425 & -.46818775 to -.20324075 \\
\hline Aref et al. (2013) & -0.31502652 & -.4457356 to -.18431742 \\
\hline Tewari et al. (2013) & -0.28841972 & -.41580069 to -.16103874 \\
\hline Erdogan et al. (2013) & -0.33102214 & -.46268752 to -.19935676 \\
\hline Mihu et al. (2013) & -0.3298324 & -.46139839 to -.1982664 \\
\hline Chen et al. (2014) & -0.33950841 & -.47162384 to -.20739301 \\
\hline Ohbuchi et al. (2014) & -0.33285877 & -.46454135 to -.20117618 \\
\hline Minatoya et al. (2014) & -0.32982665 & -.46143582 to -.19821748 \\
\hline Diakowska et al. (2014) & -0.33376125 & -.46553349 to -.20198898 \\
\hline Combined & -0.33375105 & -.46467104 to -.20283107 \\
\hline
\end{tabular}

melanoma (1 study), thyroid cancer (1 study), and tongue cancer (1 study). Circulating samples included serum (65 studies) and plasma (37 studies), while 5 studies did not mention the exact one. Most researches provided the mean concentrations of circulating adiponectin levels and the SDs of them. SDs from 11 studies were calculated based on the sample size and $P$ values. 96 studies had NOS scores greater than 6 along with 11 studies had scores of 5 . The main characteristics of eligible articles were listed in Table 1.

\section{Study ID}

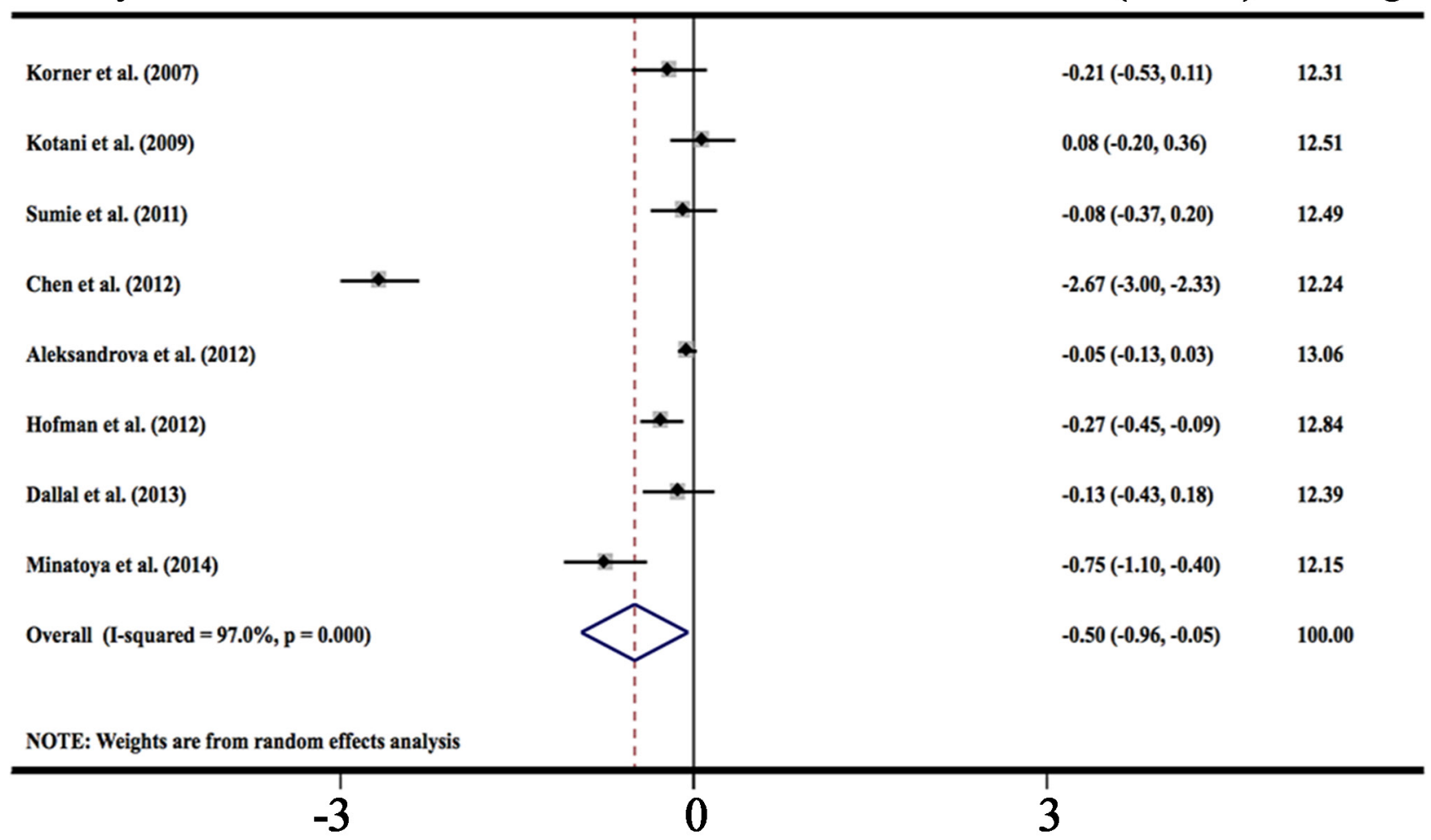

Figure 3: Forest plot of studies in circulating high molecular weight adiponectin and cancer risk. The combined SMD and $95 \%$ CIs were calculated through a random-effect model. 


\section{Circulating adiponectin levels and carcinogenesis}

Data from 107 studies were analyzed in a randomeffect model to compare circulating adiponectin levels in people with different cancers and controls. Results showed that circulating adiponectin levels in cancer cases were significantly lower than in the controls with a pooled SMD of $-0.334 \mu \mathrm{g} / \mathrm{ml}(95 \% \mathrm{CI},-0.465$ to $-0.203, P=0.000)$. Statistically significant amount of heterogeneity was observed across these studies $\left(\mathrm{I}^{2}=97.6 \%, P<0.0001\right)$, so subgroup analysis was carried out next. These results were presented in Figure 2.

HMW-adiponectin is the dominant form of adiponectin in plasma and correlates with cardiovascular disease, insulin resistance, and obesity [7, 113, 114]. But few studies have evaluated the relationship between circulating HMW-adiponectin levels and cancer risk. We analyzed data from 8 studies in a random-effect model to compare circulating HMW-adiponectin levels in people with different cancers [33, 56, 58, 72, 83, 94, 107, 108]. Results showed that circulating HMW-adiponectin levels in cancer cases were significantly lower than in the controls with a pooled SMD of $-0.502 \mu \mathrm{g} / \mathrm{ml}(95 \% \mathrm{CI}$,
-0.957 to $-0.047, P=0.000$ ), which is consistent with the results derived from total adiponectin levels. Statistically significant amount of heterogeneity was observed across these studies $\left(\mathrm{I}^{2}=97.0 \%, P<0.0001\right)$. These results were presented in Figure 3.

\section{Subgroup analysis and meta-regression}

Stratified subgroup analysis was performed to evaluate the potential sources of heterogeneity including ethnicity, cancer type, study design, blood sample, assay method, study size, study quality and mean age of cancer patients (Table 2). Lower levels of circulating adiponectin were observed in both Asian (SMD -0.555, 95\% CI, -0.812 to -0.298 ) and Caucasian people (SMD -0.269 , $95 \%$ CI, -0.400 to -0.138 ). Similar results were also presented in people with breast (SMD -0.334, 95\% CI, -0.543 to -0.126 ), colorectal (SMD $-0.496,95 \%$ CI, -0.653 to -0.339 ), endometrial (SMD $-0.594,95 \% \mathrm{CI},-0.825$ to -0.363 ), prostate (SMD $-0.892,95 \%$ CI, -1.345 to -0.438 ), thyroid (SMD $-0.358,95 \%$ CI, -0.601 to -0.116 ), tongue (SMD -1.172, 95\% CI, -1.580 to -0.764 ), gastroesophageal (SMD -0.278, 95\% CI, -0.553 to -0.004) cancer, multiple

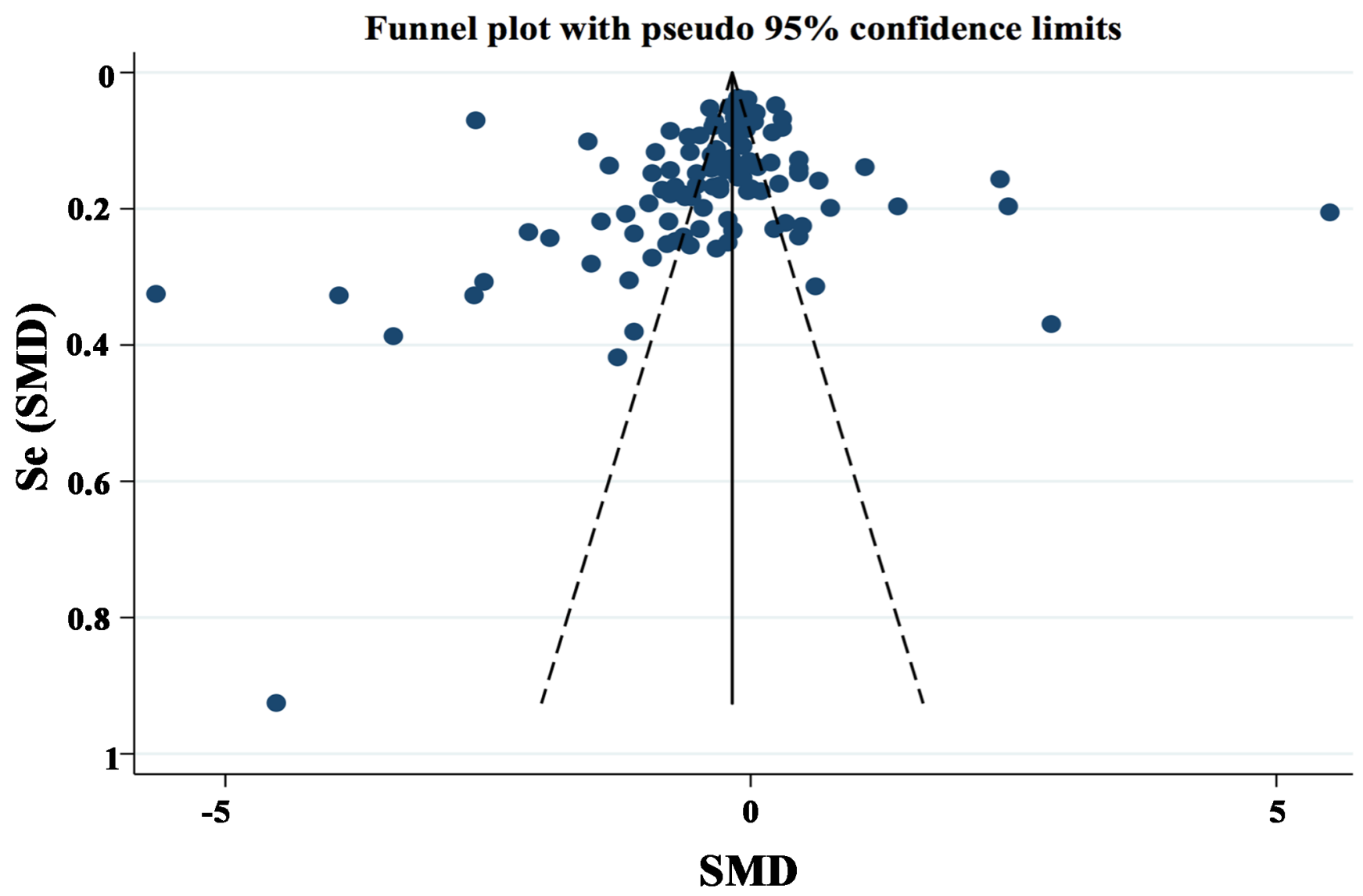

Figure 4: Funnel plot of lower adiponectin expression and cancer risk. Circles indicate included studies. 
myeloma (SMD -0.621, 95\% CI, -0.966 to -0.276 ), and acute leukemia (SMD -0.594, 95\% CI, -0.825 to -0.363 ). Notably, circulating adiponectin levels were higher in the patients with hepatocellular cancer than in controls among 7 studies included (SMD 1.385, 95\% CI, 0.240 to 2.530).

Additionally, adiponectin was significantly lower in patients who used serum as test samples (SMD -0.335, $95 \% \mathrm{CI},-0.483$ to -0.186 ), and in 37 studies who used plasma as testing samples, 26 studies showed the inverse relation of adiponectin to cancer risk. Assay method (radioimmunoassay or enzyme-linked immunosorbent assay) did not affect the results that circulating adiponectin was lower in cancer patients with pooled SMD of -0.316 and -0.266 . Study size (more or less than 100 patients) did not change the result of estimated SMD either (SMD $-0.135,95 \%$ CI, -0.299 to -0.030 ; SMD $-0.549,95 \%$ CI, -0.825 to -0.273 , respectively). Besides, no matter the mean age of cancer patients is older or younger than 60 years, decreased adiponectin levels were still exist in cancer patients (SMD $-0.489,95 \%$ CI, -0.689 to -0.288 ; SMD $-0.194,95 \%$ CI, -0.383 to -0.004 , respectively).

Next we performed meta-regression to evaluate the effect of the above factors on the estimate of SMD. In meta-regression, none of the examined factors, such as ethnicity, cancer type, study design, blood sample, assay method, study size, study quality and mean age of cancer patients was proved to be significant contributing factors.

\section{Sensitivity analysis}

Sensitivity analysis was performed by excluding one study at a time and calculating the pooled SMDs for the remaining studies. It was found that the combined SMDs were similar to one another and statistically significant. None of the studies influence the pooled results substantially in this analysis (Table 3).

\section{Publication bias}

Publication bias was assessed by funnel plot and Egger's regression test. Funnel plot shapes demonstrated a marginally asymmetrical distribution (Figure 4), accordingly we performed further analysis with Egger's test. The tested result (Figure 5) showed no evidence of publication bias $(P=0.123)$.

\section{DISCUSSION}

By integrating 107 studies, our meta-analysis revealed that lower circulating adiponectin levels were associated with higher risk of cancers. Despite the existence of heterogeneity, the disparity of adiponectin levels between malignant individuals and controls reveals the potential ability of adiponectin to serve as a biomarker for early detection of cancers.

Aberrant adiponectin secretion is associated with tumor progression, metastasis and overall prognosis. Two previous meta-analysis indicated that lower adiponectin levels were associated with higher risk of breast cancer, colorectal cancer and colorectal adenoma [115, 116]. By synthesizing 107 studies involving 19,319 cases with different malignancies, the present meta-analysis estimate the inverse association between circulating adiponectin levels and cancer risk. Moreover, through subgroup analysis, we identified that this inverse relation of adiponectin to cancer risk might be more meaningful in

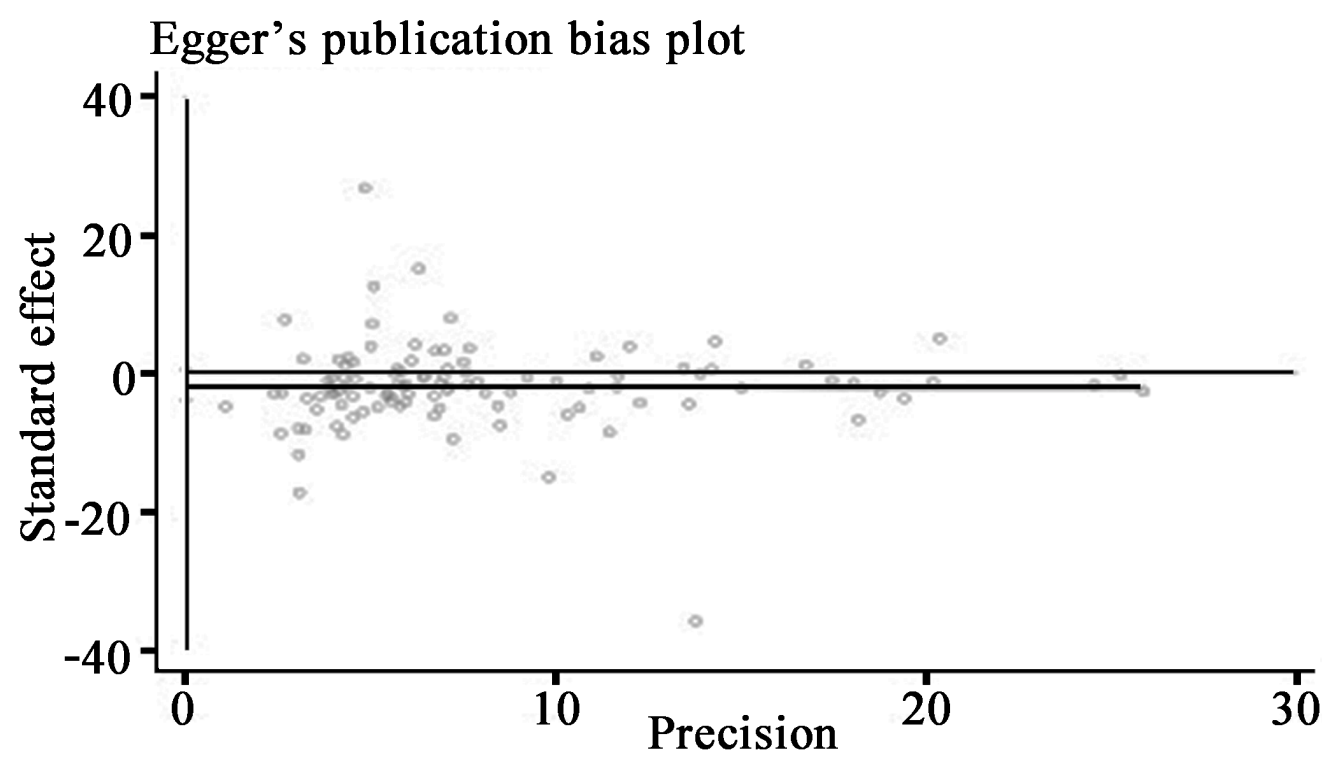

Figure 5: Egger's linear regression test for publication bias detection. 
breast, colon, endometrial, prostate, and gastroesophageal cancers. Besides, adiponectin levels tend to decrease as tumor stage increases in gastric cancer [62]. Kang et al. also indicate that breast cancer patients with less than the median adiponectin levels are easy to develop lymph node metastasis [82]. Low adiponectin level is the independent predictor of unfavorable prognosis in colorectal cancer [117]. These findings demonstrate that adiponectin is not only associated with cancer risk, but also correlated with tumor progression. Additionally, in our included 107 studies, 8 studies evaluated the relationship between circulating levels of adiponectin subtypes and cancer risk. The changing trend of total adiponectin was almost same with the three adiponectin subtypes in cancer patients, especially with $\mathrm{HMW}$-adiponectin, that it is inversely associated with cancer risk.

Circulating adiponectin levels are affected by various factors, including inflammatory, dietary, hormonal, genetic, and medicine. One of possible explanations for decreased adiponectin levels in malignancies is the sustained inflammatory status of cancer patients leads to the increased proinflammatory cytokines such as TNF- $\alpha$ and IL-6, which are all reported to suppress adiponectin transcription and translation in adipocyte cell line [118, 119]. Besides, in obesity-related cancers, adiponectin may control its own production through a negative feedback loop during the development of obesity [120]. Moreover, dietary with lower intake of fiber and magnesium can also reduce circulating adiponectin levels [121].

However, elevated adiponectin levels are also reported in hepatocellular carcinoma. Since adiponectin is mainly degraded in the liver and adiponectin levels are elevated in advanced disease including cirrhosis and virusrelated cancer $[61,122]$. One possible explanation for increased adiponectin level in hepatocellular carcinoma might be due to deteriorated hepatic metabolism resulted from repeated necroinflammation and regeneration. Besides, conflicting results also exist in clinical studies of pancreatic cancer that both higher and lower adiponectin levels are reported to be associated with cancer risk [45, 50]. After reviewing the pancreatic cancer studies with higher levels of adiponectin, we found that almost half of them were accompanied with jaundice [45]. Since cholestasis would lead to the chronic liver deterioration, it is possible that increased adiponectin levels might be due to the reduced degradation.

The peripheral functions of adiponectin are mainly mediated through AdipoR1 and AdipoR2. The expression levels of AdipoRs vary between malignant tissues and their peritumoral normal counterparts. The upregulation of AdipoR1 and AdipoR2 are reported in gastric carcinoma [123], whereas decreased in prostate cancer tissues compared with the nonmalignant tissues [36]. Increased expression of AdipoRs may be the response of reduced circulating as well as local adiponectin levels and reduced expression suggests that the sensitivity of AdipoRs to adiponectin is decreased in tumor tissues. Yabushita et al. indicate that poor expression of AdipoR1 is associated with tumor invasion and lymph node metastasis, as well as poor prognosis in endometrial cancer patients [124]. A study of non-small cell lung cancer also indicates that patients with higher expression of AdipoR1 have longer overall survival and AdipoR2 expression is inversely correlated with tumor size [125]. Those findings further illustrate the protective role of adiponectin as well as AdipoRs and shed light on exploiting them for cancer therapy. Recently, AdipoRs agonist called 355ADP is identified and might represent a new strategy to replace low adiponectin level in cancer [126].

Despite the inverse correlation between adiponectin and various cancers, the underlying mechanisms of adiponectin in potential cancer suppression are still need to elucidate. Adiponectin decreases low density lipoprotein (LDL) receptor expression in breast cancer cells through promoting autophagic flux and inhibits LDL-cholesterol-induced tumor cell proliferation [127]. Adiponectin induces the phosphorylation of p53, a tumor suppressor, which renders cell cycle arrest and apoptosis in cancer cell lines [128]. Adiponectin also inhibits leptininduced metastasis by downregulating JAK/STAT3 pathway, displaying an inverse correlation with cancer development [129]. In contrast, adiponectin promotes the angiogenesis in human chondrosarcoma by increasing vascular endothelial growth factor-A expression [130]. It is also reported to exert anti-apoptotic effects on pancreatic cancer cells through activation of AMPK/Sirtuin-1 signaling pathway [131]. Taken together, adiponectin might play a complicated role in carcinogenesis and progression of cancers.

Our study has some limitations that need to be addressed when interpreting the results. The significant heterogeneity was observed among the studies thus the conclusion should be more conservative. Although stratified analysis was conducted, none of the factors including ethnicity, cancer type, study design, blood sample, assay method, study size, study quality, and mean age of cancer patients were confirmed to contributing factors. Some possible reasons may partially explain this heterogeneity. Adiponectin levels are changed along with the tumor development. The tumor type, size, histological grade, and lymph node metastasis are the possible contributors caused heterogeneity. It is difficult for us to acquire the detailed information from the included studies. Besides, the subjects were from different regions and the lifestyle combined with diet was varied, which might influence the level of adiponectin. Since adiponectin is mainly secreted from adipose tissue, variables such as age, hormone receptor expression, menopausal status and BMI could contribute to the secretion and those factors were not fully deliberated for the complexity of tumor environment. 


\section{CONCLUSIONS}

In summary, the present study shows significant difference in circulating adiponectin levels between patients with malignancies and controls. Low circulating adiponectin level is associated with increased cancer risk, which suggests that adiponectin may serve as a potential biomarker for early detection of cancers considering its abundance in blood. Thorough understanding the roles of adiponectin and its receptors in the progression of cancers is helpful to cancer screening and promote individualized treatment.

\section{MATERIALS AND METHODS}

\section{Search strategy}

Based on the standard guidelines, a systematic search of English literature from Cochrane library, Wiley online library, PubMed was conducted to retrieve eligible studies until August 8, 2015. Searching terms included Medical Subject Heading (Mesh) and free text words "adiponectin", “ADPN", “Acrp 30", “AdipoQ", “GBP 28 " or "apM1" in combination with "neoplasm", "cancer", "carcinoma", "malignancy" or "tumor". Furthermore, we manually searched references of relevant studies to add potential research to this meta-analysis.

\section{Inclusion and exclusion criteria}

Studies were included if they met the following criteria: (i) full text case-control studies published in peerreviewed journals evaluating the relationship between circulating adiponectin concentration and carcinogenesis; (ii) all cases were diagnosed as cancer by pathological biopsy or other medical methods with blood sample obtained before any therapies and all the controls were people without any cancers. (iii) circulating adiponectin level and standard deviation (SD) of it were provided or there were enough information to estimate them. Reviews, letters or animal experiments were excluded and articles without key information to carry on further analysis were also beyond consideration. Meanwhile, if replicated patient cohort was published in different studies, only the most recent or complete one was chosen. Since all the studies included were acquired from literature, ethics committee approval was not needed.

\section{Data extraction}

Based on the checklist of MOOSE (Meta-analysis Of Observational Studies in Epidemiology) [132], two reviewers (Tai W and Peng Y) extracted the following data independently from eligible studies: the last name of first author, year of publication, geographic region, ethnicity, tumor type, study design, sample type, adiponectin assay method, number of patients and controls, assay source, mean \pm SD of adiponectin concentration. Disagreement was resolved by discussion until the two reviewers reached a consensus.

\section{Quality assessment of included studies}

Two reviewers (Tai W and Peng Y) independently assessed the quality of each included study according to the Newcastle-Ottawa Quality Assessment Scale (NOS) [133] ranges from 0 to 9 stars. Studies with more than 6 stars were considered as high-quality studies. Any disagreement was resolved by discussion and reevaluation.

\section{Statistical analysis}

We acquired the mean \pm SD of circulating adiponectin levels from cases and controls through three ways. The most accurate method was extracted them from the original research directly. However, a few studies presented the results as median values or standard error. In that case, we regarded median value as mean value considering the large sample size and calculated the SD value by using standard error and population number. If necessary, we contacted the author for detailed information. Standard mean differences (SMDs) and the corresponding 95\% confidence intervals (CIs) of circulating adiponectin were calculated for all the eligible studies. Cochran's Q-test was performed to test the heterogeneity of included studies and $P<0.05$ was considered statistically significant. Higgins I-squared statistic was applied to offer evidence of heterogeneity with $\mathrm{I}^{2}>50 \%$ suggesting significant heterogeneity. The pooled SMD and $95 \%$ CI was calculated using a fixedeffects model if the heterogeneity was not significant, otherwise a random-effect model was employed and subgroup analyses and meta-regression were adopted to detect the potential cause of heterogeneity.

Sensitivity analysis was executed to detect the robustness of the results. Publication bias was evaluated by use of funnel plot and Egger's linear regression test. The Stata 13.0 software (Stata Corporation, College Station, TX, USA) was used to perform all the statistical analysis. All $P$ values were two-sided.

\section{CONFLICTS OF INTEREST}

The authors have no relevant affiliations or financial involvement with any organization or entity with a financial conflict with any materials discussed in the paper. All authors declare that there is no conflict of interest regarding the publication of this work. 


\section{GRANT SUPPORT}

This study was supported by the National Natural Science Foundation of China (No. 81472527) and National Supporting Program for Science and Technology of China (No. 2014BAI04B06).

\section{REFERENCES}

1. Bray F, Ren JS, Masuyer E and Ferlay J. Global estimates of cancer prevalence for 27 sites in the adult population in 2008. Int J Cancer. 2013; 132:1133-1145.

2. Kelly T, Yang W, Chen CS, Reynolds K and He J. Global burden of obesity in 2005 and projections to 2030. Int J Obes (Lond). 2008; 32:1431-1437.

3. Calle EE and Kaaks R. Overweight, obesity and cancer: epidemiological evidence and proposed mechanisms. Nat Rev Cancer. 2004; 4:579-591.

4. Trevellin E, Scarpa M, Carraro A, Lunardi F, Kotsafti A, Porzionato A, Saadeh L, Cagol M, Alfieri R, Tedeschi U, Calabrese F, Castoro C and Vettor R. Esophageal adenocarcinoma and obesity: peritumoral adipose tissue plays a role in lymph node invasion. Oncotarget. 2015; 6:11203-11215. doi: 10.18632/oncotarget.3587.

5. Scherer PE, Williams S, Fogliano M, Baldini G and Lodish $\mathrm{HF}$. A novel serum protein similar to $\mathrm{C} 1 \mathrm{q}$, produced exclusively in adipocytes. J Biol Chem. 1995; 270:2674626749 .

6. Hu E, Liang P and Spiegelman BM. AdipoQ is a novel adipose-specific gene dysregulated in obesity. J Biol Chem. 1996; 271:10697-10703.

7. Fujimatsu D, Kotooka N, Inoue T, Nishiyama M and Node $\mathrm{K}$. Association between high molecular weight adiponectin levels and metabolic parameters. J Atheroscler Thromb. 2009; 16:553-559.

8. Yamauchi T, Kamon J, Ito Y, Tsuchida A, Yokomizo T, Kita S, Sugiyama T, Miyagishi M, Hara K, Tsunoda M, Murakami K, Ohteki T, Uchida S, Takekawa S, Waki H, Tsuno NH, et al. Cloning of adiponectin receptors that mediate antidiabetic metabolic effects. Nature. 2003; 423:762-769.

9. Hug C, Wang J, Ahmad NS, Bogan JS, Tsao TS and Lodish HF. T-cadherin is a receptor for hexameric and highmolecular-weight forms of Acrp30/adiponectin. Proc Natl Acad Sci USA. 2004; 101:10308-10313.

10. Ye R and Scherer PE. Adiponectin, driver or passenger on the road to insulin sensitivity? Mol Metab. 2013; 2:133-141.

11. Liu YM, Lacorte JM, Viguerie N, Poitou C, Pelloux V, Guy-Grand B, Coussieu C, Langin D, Basdevant A and Clement K. Adiponectin gene expression in subcutaneous adipose tissue of obese women in response to short-term very low calorie diet and refeeding. J Clin Endocrinol Metab. 2003; 88:5881-5886.

12. Miyoshi Y, Funahashi T, Kihara S, Taguchi T, Tamaki
Y, Matsuzawa Y and Noguchi S. Association of serum adiponectin levels with breast cancer risk. Clin Cancer Res. 2003; 9:5699-5704.

13. Goktas S, Yilmaz MI, Caglar K, Sonmez A, Kilic S and Bedir S. Prostate cancer and adiponectin. Urology. 2005; 65:1168-1172.

14. Gu C, Qu Y, Zhang G, Sun L, Zhu Y and Ye D. A single nucleotide polymorphism in ADIPOQ predicts biochemical recurrence after radical prostatectomy in localized prostate cancer. Oncotarget. 2015; 6:32205-32211. doi: 10.18632/ oncotarget.4980.

15. Soliman PT, Wu D, Tortolero-Luna G, Schmeler KM, Slomovitz BM, Bray MS, Gershenson DM and Lu KH. Association between adiponectin, insulin resistance, and endometrial cancer. Cancer. 2006; 106:2376-2381.

16. Fukumoto J, Otake T, Tajima O, Tabata S, Abe H, Mizoue T, Ohnaka K and Kono S. Adiponectin and colorectal adenomas: self defense forces health study. Cancer Sci. 2008; 99:781-786.

17. Dieudonne MN, Bussiere M, Dos Santos E, Leneveu MC, Giudicelli Y and Pecquery R. Adiponectin mediates antiproliferative and apoptotic responses in human MCF7 breast cancer cells. Biochem Biophys Res Commun. 2006; 345:271-279.

18. Zhang L, Wen K, Han X, Liu R and Qu Q. Adiponectin mediates antiproliferative and apoptotic responses in endometrial carcinoma by the AdipoRs/AMPK pathway. Gynecol Oncol. 2015; 137:311-320.

19. Pezzilli R, Barassi A, Corsi MM, Morselli-Labate AM, Campana D, Casadei R, Santini D, Corinaldesi R and D'Eril GM. Serum leptin, but not adiponectin and receptor for advanced glycation end products, is able to distinguish autoimmune pancreatitis from both chronic pancreatitis and pancreatic neoplasms. Scand J Gastroenterol. 2010; 45:9399.

20. Chen MJ, Yeh YT, Lee KT, Tsai CJ, Lee HH and Wang SN. The promoting effect of adiponectin in hepatocellular carcinoma. J Surg Oncol. 2012; 106:181-187.

21. Mitsiades N, Pazaitou-Panayiotou K, Aronis KN, Moon HS, Chamberland JP, Liu X, Diakopoulos KN, Kyttaris V, Panagiotou V, Mylvaganam G, Tseleni-Balafouta S and Mantzoros CS. Circulating adiponectin is inversely associated with risk of thyroid cancer: in vivo and in vitro studies. J Clin Endocrinol Metab. 2011; 96:E2023-2028.

22. Spyridopoulos TN, Dessypris N, Antoniadis AG, Gialamas $\mathrm{S}$, Antonopoulos CN, Katsifoti K, Adami HO, Chrousos GP and Petridou ET. Insulin resistance and risk of renal cell cancer: a case-control study. Hormones (Athens). 2012; 11:308-315.

23. Liao LM, Weinstein SJ, Pollak M, Li Z, Virtamo J, Albanes D, Chow WH and Purdue MP. Prediagnostic circulating adipokine concentrations and risk of renal cell carcinoma in male smokers. Carcinogenesis. 2013; 34:109-112.

24. Liao LM, Schwartz K, Pollak M, Graubard BI, Li Z, 
Ruterbusch J, Rothman N, Davis F, Wacholder S, Colt J, Chow WH and Purdue MP. Serum leptin and adiponectin levels and risk of renal cell carcinoma. Obesity (Silver Spring). 2013; 21:1478-1485.

25. Petridou E, Mantzoros CS, Dessypris N, Dikalioti SK and Trichopoulos D. Adiponectin in relation to childhood myeloblastic leukaemia. Br J Cancer. 2006; 94:156-160.

26. Moschovi M, Trimis G, Vounatsou M, Katsibardi K, Margeli A, Damianos A, Chrousos G and Papassotiriou I. Serial plasma concentrations of adiponectin, leptin, and resistin during therapy in children with acute lymphoblastic leukemia. J Pediatr Hematol Oncol. 2010; 32:e8-13.

27. Aref S, Ibrahim L, Azmy E and Al Ashary R. Impact of serum adiponectin and leptin levels in acute leukemia. Hematology. 2013; 18:198-203.

28. Petridou ET, Dessypris N, Panagopoulou P, Sergentanis $\mathrm{TN}$, Mentis AF, Pourtsidis A, Polychronopoulou S, Kalmanti M, Athanasiadou-Piperopoulou F and Moschovi M. Adipocytokines in relation to Hodgkin lymphoma in children. Pediatr Blood Cancer. 2010; 54:311-315.

29. Pamuk GE, Turgut B, Demir M and Vural O. Increased adiponectin level in non-Hodgkin lymphoma and its relationship with interleukin-10. Correlation with clinical features and outcome. J Exp Clin Cancer Res. 2006; 25:537-541.

30. Petridou ET, Sergentanis TN, Dessypris N, Vlachantoni IT, Tseleni-Balafouta S, Pourtsidis A, Moschovi M, Polychronopoulou S, Athanasiadou-Piperopoulou F, Kalmanti $\mathrm{M}$ and Mantzoros CS. Serum adiponectin as a predictor of childhood non-Hodgkin's lymphoma: a nationwide case-control study. J Clin Oncol. 2009; 27:50495055 .

31. Conroy SM, Maskarinec G, Morimoto Y, Franke AA, Cooney RV, Wilkens LR, Goodman MT, Hernadez BY, Le Marchand L, Henderson BE and Kolonel LN. Non-hodgkin lymphoma and circulating markers of inflammation and adiposity in a nested case-control study: the multiethnic cohort. Cancer Epidemiol Biomarkers Prev. 2013; 22:337347.

32. Dalamaga M, Karmaniolas K, Panagiotou A, Hsi A, Chamberland J, Dimas C, Lekka A and Mantzoros CS. Low circulating adiponectin and resistin, but not leptin, levels are associated with multiple myeloma risk: a case-control study. Cancer Causes Control. 2009; 20:193-199.

33. Hofmann JN, Liao LM, Pollak MN, Wang Y, Pfeiffer RM, Baris D, Andreotti G, Lan Q, Landgren O, Rothman N and Purdue MP. A prospective study of circulating adipokine levels and risk of multiple myeloma. Blood. 2012; 120:4418-4420.

34. Antoniadis AG, Petridou ET, Antonopoulos CN, Dessypris N, Panagopoulou P, Chamberland JP, Adami HO, Gogas $\mathrm{H}$ and Mantzoros CS. Insulin resistance in relation to melanoma risk. Melanoma Res. 2011; 21:541-546.

35. Baillargeon J, Platz EA, Rose DP, Pollock BH, Ankerst DP,
Haffner S, Higgins B, Lokshin A, Troyer D, Hernandez J, Lynch S, Leach RJ and Thompson IM. Obesity, adipokines, and prostate cancer in a prospective population-based study. Cancer Epidemiol Biomarkers Prev. 2006; 15:1331-1335.

36. Michalakis K, Williams CJ, Mitsiades N, Blakeman J, Balafouta-Tselenis S, Giannopoulos A and Mantzoros CS. Serum adiponectin concentrations and tissue expression of adiponectin receptors are reduced in patients with prostate cancer: a case control study. Cancer Epidemiol Biomarkers Prev. 2007; 16:308-313.

37. Housa D, Vernerova Z, Heracek J, Prochazka B, Cechak $\mathrm{P}$, Kuncova $\mathrm{J}$ and Haluzik M. Adiponectin as a potential marker of prostate cancer progression: studies in organconfined and locally advanced prostate cancer. Physiol Res. 2008; 57:451-458.

38. Grosman H, Fabre B, Mesch V, Lopez MA, Schreier L, Mazza O and Berg G. Lipoproteins, sex hormones and inflammatory markers in association with prostate cancer. Aging Male. 2010; 13:87-92.

39. Li H, Stampfer MJ, Mucci L, Rifai N, Qiu W, Kurth T and Ma J. A 25-year prospective study of plasma adiponectin and leptin concentrations and prostate cancer risk and survival. Clin Chem. 2010; 56:34-43.

40. Al Khaldi RM, Al Mulla F, Al Awadhi S, Kapila K and Mojiminiyi OA. Associations of single nucleotide polymorphisms in the adiponectin gene with adiponectin levels and cardio-metabolic risk factors in patients with cancer. Dis Markers. 2011; 30:197-212.

41. Dhillon PK, Penney KL, Schumacher F, Rider JR, Sesso HD, Pollak M, Fiorentino M, Finn S, Loda M, Rifai N, Mucci LA, Giovannucci E, Stampfer MJ and Ma J. Common polymorphisms in the adiponectin and its receptor genes, adiponectin levels and the risk of prostate cancer. Cancer Epidemiol Biomarkers Prev. 2011; 20:2618-2627.

42. Lopez Fontana CM, Maselli ME, Perez Elizalde RF, Di Milta Monaco NA, Uvilla Recupero AL and Lopez Laur JD. Leptin increases prostate cancer aggressiveness. J Physiol Biochem. 2011; 67:531-538.

43. Tewari R, Rajender S, Natu SM, Goel A, Dalela D, Goel $\mathrm{MM}$ and Tondon P. Significance of obesity markers and adipocytokines in high grade and high stage prostate cancer in North Indian men - a cross-sectional study. Cytokine. 2013; 63:130-134.

44. Touvier M, Fezeu L, Ahluwalia N, Julia C, Charnaux N, Sutton A, Mejean C, Latino-Martel P, Hercberg S, Galan $\mathrm{P}$ and Czernichow S. Association between prediagnostic biomarkers of inflammation and endothelial function and cancer risk: a nested case-control study. Am J Epidemiol. 2013; 177:3-13.

45. Chang MC, Chang YT, Su TC, Yang WS, Chen CL, Tien YW, Liang PC, Wei SC and Wong JM. Adiponectin as a potential differential marker to distinguish pancreatic cancer and chronic pancreatitis. Pancreas. 2007; 35:16-21.

46. Stolzenberg-Solomon RZ, Weinstein S, Pollak M, Tao 
Y, Taylor PR, Virtamo J and Albanes D. Prediagnostic adiponectin concentrations and pancreatic cancer risk in male smokers. Am J Epidemiol. 2008; 168:1047-1055.

47. Dalamaga M, Migdalis I, Fargnoli JL, Papadavid E, Bloom E, Mitsiades N, Karmaniolas K, Pelecanos N, TseleniBalafouta S, Dionyssiou-Asteriou A and Mantzoros CS. Pancreatic cancer expresses adiponectin receptors and is associated with hypoleptinemia and hyperadiponectinemia: a case-control study. Cancer Causes Control. 2009; 20:625633.

48. Krechler T, Zeman M, Vecka M, Macasek J, Jachymova M, Zima T and Zak A. Leptin and adiponectin in pancreatic cancer: connection with diabetes mellitus. Neoplasma. 2011; 58:58-64.

49. Grote VA, Rohrmann S, Dossus L, Nieters A, Halkjaer J, Tjonneland A, Overvad K, Stegger J, Chabbert-Buffet $\mathrm{N}$, Boutron-Ruault MC, Clavel-Chapelon F, Teucher B, Becker S, Montonen J, Boeing H, Trichopoulou A, et al. The association of circulating adiponectin levels with pancreatic cancer risk: a study within the prospective EPIC cohort. Int J Cancer. 2012; 130:2428-2437.

50. Bao Y, Giovannucci EL, Kraft P, Stampfer MJ, Ogino S, Ma J, Buring JE, Sesso HD, Lee IM, Gaziano JM, Rifai N, Pollak MN, Cochrane BB, Kaklamani V, Lin JH, Manson JE, et al. A prospective study of plasma adiponectin and pancreatic cancer risk in five US cohorts. J Natl Cancer Inst. 2013; 105:95-103.

51. Jamieson NB, Brown DJ, Michael Wallace A and McMillan DC. Adiponectin and the systemic inflammatory response in weight-losing patients with non-small cell lung cancer. Cytokine. 2004; 27:90-92.

52. Petridou ET, Mitsiades N, Gialamas S, Angelopoulos M, Skalkidou A, Dessypris N, Hsi A, Lazaris N, Polyzos A, Syrigos C, Brennan AM, Tseleni-Balafouta $\mathrm{S}$ and Mantzoros CS. Circulating adiponectin levels and expression of adiponectin receptors in relation to lung cancer: two case-control studies. Oncology. 2007; 73:261269.

53. Karapanagiotou EM, Tsochatzis EA, Dilana KD, Tourkantonis I, Gratsias I and Syrigos KN. The significance of leptin, adiponectin, and resistin serum levels in non-small cell lung cancer (NSCLC). Lung Cancer. 2008; 61:391-397.

54. Gulen ST, Karadag F, Karul AB, Kilicarslan N, Ceylan E, Kuman NK and Cildag O. Adipokines and systemic inflammation in weight-losing lung cancer patients. Lung. 2012; 190:327-332.

55. Kerenidi T, Lada M, Tsaroucha A, Georgoulias P, Mystridou P and Gourgoulianis KI. Clinical significance of serum adipokines levels in lung cancer. Med Oncol. 2013; 30:507.

56. Kotani K, Wakai K, Shibata A, Fujita Y, Ogimoto I, Naito M, Kurozawa Y, Suzuki H, Yoshimura T and Tamakoshi A. Serum adiponectin multimer complexes and liver cancer risk in a large cohort study in Japan. Asian Pac J Cancer Prev. 2009; 10 Suppl:87-90.
57. Liu CJ, Chen PJ, Lai MY, Liu CH, Chen CL, Kao JH and Chen DS. High serum adiponectin correlates with advanced liver disease in patients with chronic hepatitis B virus infection. Hepatol Int. 2009; 3:364-370.

58. Sumie S, Kawaguchi T, Kuromatsu R, Takata A, Nakano M, Satani M, Yamada S, Niizeki T, Torimura T and Sata M. Total and high molecular weight adiponectin and hepatocellular carcinoma with HCV infection. PLoS One. 2011; 6:e26840.

59. Khattab MA, Eslam M, Mousa YI, Ela-adawy N, Fathy S, Shatat M, Abd-Aalhalim H, Kamal A and Sharawe MA. Association between metabolic abnormalities and hepatitis C-related hepatocellular carcinoma. Ann Hepatol. 2012; 11:487-494.

60. Sadik NA, Ahmed A and Ahmed S. The significance of serum levels of adiponectin, leptin, and hyaluronic acid in hepatocellular carcinoma of cirrhotic and noncirrhotic patients. Hum Exp Toxicol. 2012; 31:311-321.

61. Chen CL, Yang WS, Yang HI, Chen CF, You SL, Wang LY, Lu SN, Liu CJ, Kao JH, Chen PJ, Chen DS and Chen CJ. Plasma adipokines and risk of hepatocellular carcinoma in chronic hepatitis B virus-infected carriers: a prospective study in taiwan. Cancer Epidemiol Biomarkers Prev. 2014; 23:1659-1671.

62. Ishikawa M, Kitayama J, Kazama S, Hiramatsu T, Hatano K and Nagawa $\mathrm{H}$. Plasma adiponectin and gastric cancer. Clin Cancer Res. 2005; 11:466-472.

63. Nakajima TE, Yamada Y, Hamano T, Furuta K, Gotoda $\mathrm{T}$, Katai H, Kato K, Hamaguchi $\mathrm{T}$ and Shimada $\mathrm{Y}$. Adipocytokine levels in gastric cancer patients: resistin and visfatin as biomarkers of gastric cancer. J Gastroenterol. 2009; 44:685-690.

64. Seker M, Bilici A, Sonmez B, Ustaalioglu BB, Gumus M, Gozu H, Sargin M, Orcun A, Gezen C, Eser M, Bildik N and Salepci T. The association of serum adiponectin levels with histopathological variables in gastric cancer patients. Med Oncol. 2010; 27:1319-1323.

65. Diakowska D, Markocka-Maczka K, Szelachowski P and Grabowski K. Serum levels of resistin, adiponectin, and apelin in gastroesophageal cancer patients. Dis Markers. 2014; 2014:619649.

66. Diao Y, Li H, Li H, Zhou Y, Ma Q, Wang Y and Li D. Association of serum levels of lipid and its novel constituents with the different stages of esophageal carcinoma. Lipids Health Dis. 2009; 8:48.

67. Yildirim A, Bilici M, Cayir K, Yanmaz V, Yildirim S and Tekin SB. Serum adiponectin levels in patients with esophageal cancer. Jpn J Clin Oncol. 2009; 39:92-96.

68. Nakajima TE, Yamada Y, Hamano T, Furuta K, Oda I, Kato H, Kato K, Hamaguchi T and Shimada Y. Adipocytokines and squamous cell carcinoma of the esophagus. J Cancer Res Clin Oncol. 2010; 136:261-266.

69. Cust AE, Kaaks R, Friedenreich C, Bonnet F, Laville M, Lukanova A, Rinaldi S, Dossus L, Slimani N, Lundin E, 
Tjonneland A, Olsen A, Overvad K, Clavel-Chapelon F, Mesrine S, Joulin V, et al. Plasma adiponectin levels and endometrial cancer risk in pre- and postmenopausal women. J Clin Endocrinol Metab. 2007; 92:255-263.

70. Ashizawa N, Yahata T, Quan J, Adachi S, Yoshihara K and Tanaka K. Serum leptin-adiponectin ratio and endometrial cancer risk in postmenopausal female subjects. Gynecol Oncol. 2010; 119:65-69.

71. Friedenreich CM, Langley AR, Speidel TP, Lau DC, Courneya KS, Csizmadi I, Magliocco AM, Yasui Y and Cook LS. Case-control study of markers of insulin resistance and endometrial cancer risk. Endocr Relat Cancer. 2012; 19:785-792.

72. Dallal CM, Brinton LA, Bauer DC, Buist DS, Cauley JA, Hue TF, Lacroix A, Tice JA, Chia VM, Falk R, Pfeiffer R, Pollak M, Veenstra TD, Xu X and Lacey JV, Jr. Obesity-related hormones and endometrial cancer among postmenopausal women: a nested case-control study within the B FIT cohort. Endocr Relat Cancer. 2013; 20:151-160.

73. Dossus L, Lukanova A, Rinaldi S, Allen N, Cust AE, Becker S, Tjonneland A, Hansen L, Overvad K, ChabbertBuffet N, Mesrine S, Clavel-Chapelon F, Teucher B, Chang-Claude J, Boeing H, Drogan D, et al. Hormonal, metabolic, and inflammatory profiles and endometrial cancer risk within the EPIC cohort--a factor analysis. Am J Epidemiol. 2013; 177:787-799.

74. Erdogan S, Sezer S, Baser E, Gun-Eryilmaz O, Gungor T, Uysal S and Yilmaz FM. Evaluating vaspin and adiponectin in postmenopausal women with endometrial cancer. Endocr Relat Cancer. 2013; 20:669-675.

75. Luhn P, Dallal CM, Weiss JM, Black A, Huang WY, Lacey JV, Jr., Hayes RB, Stanczyk FZ, Wentzensen N and Brinton LA. Circulating adipokine levels and endometrial cancer risk in the prostate, lung, colorectal, and ovarian cancer screening trial. Cancer Epidemiol Biomarkers Prev. 2013; 22:1304-1312.

76. Ma Y, Liu Z, Zhang Y and Lu B. Serum leptin, adiponectin and endometrial cancer risk in Chinese women. J Gynecol Oncol. 2013; 24:336-341.

77. Mihu D, Ciortea R and Mihu CM. Abdominal adiposity through adipocyte secretion products, a risk factor for endometrial cancer. Gynecol Endocrinol. 2013; 29:448-451.

78. Ohbuchi Y, Suzuki Y, Hatakeyama I, Nakao Y, Fujito A, Iwasaka $\mathrm{T}$ and Isaka K. A lower serum level of middle-molecular-weight adiponectin is a risk factor for endometrial cancer. Int J Clin Oncol. 2014; 19:667-673.

79. Mantzoros C, Petridou E, Dessypris N, Chavelas C, Dalamaga M, Alexe DM, Papadiamantis Y, Markopoulos C, Spanos E, Chrousos G and Trichopoulos D. Adiponectin and breast cancer risk. J Clin Endocrinol Metab. 2004; 89:1102-1107.

80. Chen DC, Chung YF, Yeh YT, Chaung HC, Kuo FC, Fu
OY, Chen HY, Hou MF and Yuan SS. Serum adiponectin and leptin levels in Taiwanese breast cancer patients. Cancer Lett. 2006; 237:109-114.

81. Hou WK, Xu YX, Yu T, Zhang L, Zhang WW, Fu CL, Sun $\mathrm{Y}, \mathrm{Wu} \mathrm{Q}$ and Chen L. Adipocytokines and breast cancer risk. Chin Med J (Engl). 2007; 120:1592-1596.

82. Kang JH, Yu BY and Youn DS. Relationship of serum adiponectin and resistin levels with breast cancer risk. J Korean Med Sci. 2007; 22:117-121.

83. Korner A, Pazaitou-Panayiotou K, Kelesidis T, Kelesidis I, Williams CJ, Kaprara A, Bullen J, Neuwirth A, Tseleni S, Mitsiades N, Kiess W and Mantzoros CS. Total and highmolecular-weight adiponectin in breast cancer: in vitro and in vivo studies. J Clin Endocrinol Metab. 2007; 92:10411048.

84. Tworoger SS, Eliassen AH, Kelesidis T, Colditz GA, Willett WC, Mantzoros CS and Hankinson SE. Plasma adiponectin concentrations and risk of incident breast cancer. J Clin Endocrinol Metab. 2007; 92:1510-1516.

85. Cust AE, Stocks T, Lukanova A, Lundin E, Hallmans G, Kaaks R, Jonsson $\mathrm{H}$ and Stattin P. The influence of overweight and insulin resistance on breast cancer risk and tumour stage at diagnosis: a prospective study. Breast Cancer Res Treat. 2009; 113:567-576.

86. Hancke K, Grubeck D, Hauser N, Kreienberg R and Weiss JM. Adipocyte fatty acid-binding protein as a novel prognostic factor in obese breast cancer patients. Breast Cancer Res Treat. 2010; 119:367-367.

87. Shahar S, Salleh RM, Ghazali AR, Koon PB and Mohamud WN. Roles of adiposity, lifetime physical activity and serum adiponectin in occurrence of breast cancer among Malaysian women in Klang Valley. Asian Pac J Cancer Prev. 2010; 11:61-66.

88. Dalamaga M, Karmaniolas K, Papadavid E, Pelekanos N, Sotiropoulos G and Lekka A. Elevated serum visfatin/ nicotinamide phosphoribosyl-transferase levels are associated with risk of postmenopausal breast cancer independently from adiponectin, leptin, and anthropometric and metabolic parameters. Menopause. 2011; 18:11981204.

89. Al Awadhi SA, Al Khaldi RM, Al Rammah T, Kapila K and Mojiminiyi OA. Associations of adipokines \& insulin resistance with sex steroids in patients with breast cancer. Indian J Med Res. 2012; 135:500-505.

90. Gulcelik MA, Colakoglu K, Dincer H, Dogan L, Yenidogan $\mathrm{E}$ and Gulcelik NE. Associations between adiponectin and two different cancers: breast and colon. Asian Pac J Cancer Prev. 2012; 13:395-398.

91. Alokail MS, Al-Daghri N, Abdulkareem A, Draz HM, Yakout SM, Alnaami AM, Sabico S, Alenad AM and Chrousos GP. Metabolic syndrome biomarkers and early breast cancer in Saudi women: evidence for the presence of 
a systemic stress response and/or a pre-existing metabolic syndrome-related neoplasia risk? BMC Cancer. 2013; 13:54.

92. Gross AL, Newschaffer CJ, Hoffman-Bolton J, Rifai N and Visvanathan K. Adipocytokines, inflammation, and breast cancer risk in postmenopausal women: a prospective study. Cancer Epidemiol Biomarkers Prev. 2013; 22:1319-1324.

93. Ollberding NJ, Kim Y, Shvetsov YB, Wilkens LR, Franke AA, Cooney RV, Maskarinec G, Hernandez BY, Henderson BE, Le Marchand L, Kolonel LN and Goodman MT. Prediagnostic leptin, adiponectin, C-reactive protein, and the risk of postmenopausal breast cancer. Cancer Prev Res (Phila). 2013; 6:188-195.

94. Minatoya M, Kutomi G, Shima H, Asakura S, Otokozawa S, Ohnishi H, Akasaka H, Miura T, Mori M and Hirata K. Relation of serum adiponectin levels and obesity with breast cancer: a Japanese case-control study. Asian Pac J Cancer Prev. 2014; 15:8325-8330.

95. Otake S, Takeda H, Suzuki Y, Fukui T, Watanabe S, Ishihama K, Saito T, Togashi H, Nakamura T, Matsuzawa $\mathrm{Y}$ and Kawata S. Association of visceral fat accumulation and plasma adiponectin with colorectal adenoma: evidence for participation of insulin resistance. Clin Cancer Res. 2005; 11:3642-3646.

96. Wei EK, Giovannucci E, Fuchs CS, Willett WC and Mantzoros CS. Low plasma adiponectin levels and risk of colorectal cancer in men: a prospective study. J Natl Cancer Inst. 2005; 97:1688-1694.

97. Stocks T, Lukanova A, Johansson M, Rinaldi S, Palmqvist R, Hallmans G, Kaaks R and Stattin P. Components of the metabolic syndrome and colorectal cancer risk; a prospective study. Int J Obes (Lond). 2008; 32:304-314.

98. Erarslan E, Turkay C, Koktener A, Koca C, Uz B and Bavbek N. Association of visceral fat accumulation and adiponectin levels with colorectal neoplasia. Dig Dis Sci. 2009; 54:862-868.

99. Guadagni F, Roselli M, Martini F, Spila A, Riondino S, D’Alessandro R, Del Monte G, Formica V, Laudisi A, Portarena I, Palmirotta R and Ferroni P. Prognostic significance of serum adipokine levels in colorectal cancer patients. Anticancer Res. 2009; 29:3321-3327.

100. Kumor A, Daniel P, Pietruczuk M and Malecka-Panas E. Serum leptin, adiponectin, and resistin concentration in colorectal adenoma and carcinoma (CC) patients. Int $\mathrm{J}$ Colorectal Dis. 2009; 24:275-281.

101. Gonullu G, Kahraman H, Bedir A, Bektas A and Yucel I. Association between adiponectin, resistin, insulin resistance, and colorectal tumors. Int J Colorectal Dis. 2010; 25:205-212.

102. Kemik O, Sumer A, Kemik AS, Hasirci I, Purisa S, Dulger AC, Demiriz B and Tuzun S. The relationship among acute-phase response proteins, cytokines and hormones in cachectic patients with colon cancer. World J Surg Oncol. 2010; 8:85.
103. Nakajima TE, Yamada Y, Hamano T, Furuta K, Matsuda $\mathrm{T}$, Fujita S, Kato K, Hamaguchi $\mathrm{T}$ and Shimada $\mathrm{Y}$. Adipocytokines as new promising markers of colorectal tumors: adiponectin for colorectal adenoma, and resistin and visfatin for colorectal cancer. Cancer Sci. 2010; 101:1286-1291.

104. Otake S, Takeda H, Fujishima S, Fukui T, Orii T, Sato T, Sasaki Y, Nishise S and Kawata S. Decreased levels of plasma adiponectin associated with increased risk of colorectal cancer. World J Gastroenterol. 2010; 16:12521257.

105. Yamaji T, Iwasaki M, Sasazuki $\mathrm{S}$ and Tsugane $\mathrm{S}$. Interaction between adiponectin and leptin influences the risk of colorectal adenoma. Cancer Res. 2010; 70:54305437.

106. Catalan V, Gomez-Ambrosi J, Rodriguez A, Ramirez B, Silva C, Rotellar F, Hernandez-Lizoain JL, Baixauli J, Valenti V, Pardo F, Salvador J and Fruhbeck G. Upregulation of the novel proinflammatory adipokines lipocalin-2, chitinase-3 like-1 and osteopontin as well as angiogenic-related factors in visceral adipose tissue of patients with colon cancer. J Nutr Biochem. 2011; 22:634641.

107. Aleksandrova K, Boeing H, Jenab M, Bueno-de-Mesquita HB, Jansen E, van Duijnhoven FJ, Fedirko V, Rinaldi S, Romieu I, Riboli E, Romaguera D, Westphal S, Overvad K, Tjonneland A, Boutron-Ruault MC, Clavel-Chapelon F, et al. Total and high-molecular weight adiponectin and risk of colorectal cancer: the European Prospective Investigation into Cancer and Nutrition Study. Carcinogenesis. 2012; 33:1211-1218.

108. Chen MW, Ye S, Zhao LL, Wang SY, Li YX, Yu CJ, Xie HJ and Wang YM. Association of plasma total and highmolecular-weight adiponectin with risk of colorectal cancer: an observational study in Chinese male. Med Oncol. 2012; 29:3129-3135.

109. Touvier M, Fezeu L, Ahluwalia N, Julia C, Charnaux N, Sutton A, Mejean C, Latino-Martel P, Hercberg S, Galan P and Czernichow S. Pre-diagnostic levels of adiponectin and soluble vascular cell adhesion molecule-1 are associated with colorectal cancer risk. World J Gastroenterol. 2012; 18:2805-2812.

110. Danese E, Minicozzi AM, Montagnana M, De Manzoni G, Lippi G and Guidi GC. Lack of an association between circulating adiponectin levels and risk of colorectal adenoma. Clin Lab. 2013; 59:211-214.

111. Song M, Zhang X, Wu K, Ogino S, Fuchs CS, Giovannucci EL and Chan AT. Plasma adiponectin and soluble leptin receptor and risk of colorectal cancer: a prospective study. Cancer Prev Res (Phila). 2013; 6:875-885.

112. Guo XH, Wang JY, Gao Y, Gao M, Yu GY, Xiang RL, Li L, Yang NY, Cong X, Xu XY, Li SL, Peng X and Wu LL. Decreased adiponectin level is associated with aggressive phenotype of tongue squamous cell carcinoma. Cancer Sci. 2013; 104:206-213. 
113. Inoue $\mathrm{T}$, Kotooka N, Morooka $\mathrm{T}$, Komoda H, Uchida $\mathrm{T}$, Aso Y, Inukai T, Okuno T and Node K. High molecular weight adiponectin as a predictor of long-term clinical outcome in patients with coronary artery disease. Am J Cardiol. 2007; 100:569-574.

114. Hara K, Horikoshi M, Yamauchi T, Yago H, Miyazaki $\mathrm{O}$, Ebinuma $\mathrm{H}$, Imai $\mathrm{Y}$, Nagai $\mathrm{R}$ and Kadowaki $\mathrm{T}$. Measurement of the high-molecular weight form of adiponectin in plasma is useful for the prediction of insulin resistance and metabolic syndrome. Diabetes Care. 2006; 29:1357-1362.

115. Ye J, Jia J, Dong S, Zhang C, Yu S, Li L, Mao C, Wang D, Chen J and Yuan G. Circulating adiponectin levels and the risk of breast cancer: a meta-analysis. Eur J Cancer Prev. 2014; 23:158-165.

116. An W, Bai Y, Deng SX, Gao J, Ben QW, Cai QC, Zhang HG and Li ZS. Adiponectin levels in patients with colorectal cancer and adenoma: a meta-analysis. Eur J Cancer Prev. 2012; 21:126-133.

117. Ferroni P, Palmirotta R, Spila A, Martini F, Raparelli V, Fossile E, Mariotti S, Del Monte G, Buonomo O, Roselli $\mathrm{M}$ and Guadagni F. Prognostic significance of adiponectin levels in non-metastatic colorectal cancer. Anticancer Res. 2007; 27:483-489.

118. Maeda N, Shimomura I, Kishida K, Nishizawa H, Matsuda M, Nagaretani H, Furuyama N, Kondo H, Takahashi M, Arita Y, Komuro R, Ouchi N, Kihara S, Tochino Y, Okutomi K, Horie M, et al. Diet-induced insulin resistance in mice lacking adiponectin/ACRP30. Nat Med. 2002; 8:731-737.

119. Fasshauer M, Kralisch S, Klier M, Lossner U, Bluher M, Klein J and Paschke R. Adiponectin gene expression and secretion is inhibited by interleukin-6 in 3T3-L1 adipocytes. Biochem Biophys Res Commun. 2003; 301:1045-1050.

120. Bauche IB, Ait El Mkadem S, Rezsohazy R, Funahashi T, Maeda N, Miranda LM and Brichard SM. Adiponectin downregulates its own production and the expression of its AdipoR2 receptor in transgenic mice. Biochem Biophys Res Commun. 2006; 345:1414-1424.

121. Qi L, Rimm E, Liu S, Rifai N and Hu FB. Dietary glycemic index, glycemic load, cereal fiber, and plasma adiponectin concentration in diabetic men. Diabetes Care. 2005; 28:1022-1028.

122. Tietge UJ, Boker KH, Manns MP and Bahr MJ. Elevated circulating adiponectin levels in liver cirrhosis are associated with reduced liver function and altered hepatic hemodynamics. Am J Physiol Endocrinol Metab. 2004; 287:E82-89

123. Barresi V, Grosso M, Giuffre G, Tuccari G and Barresi $\mathrm{G}$. The expression of adiponectin receptors Adipo-R1 and Adipo-R2 is associated with an intestinal histotype and longer survival in gastric carcinoma. J Clinical Pathol. 2009; 62:705-709.
124. Yabushita H, Iwasaki K, Obayashi Y and Wakatsuki A. Clinicopathological roles of adiponectin and leptin receptors in endometrial carcinoma. Oncol Lett. 2014; 7:1109-1117.

125. Abdul-Ghafar J, Oh SS, Park SM, Wairagu P, Lee SN, Jeong Y, Eom M, Yong SJ and Jung SH. Expression of adiponectin receptor 1 is indicative of favorable prognosis in non-small cell lung carcinoma. Tohoku J Exp Med. 2013; 229:153-162.

126. Otvos L, Jr., Haspinger E, La Russa F, Maspero F, Graziano P, Kovalszky I, Lovas S, Nama K, Hoffmann R, Knappe D, Cassone M, Wade J and Surmacz E. Design and development of a peptide-based adiponectin receptor agonist for cancer treatment. BMC Biotechnol. 2011; 11:90.

127. Liu J, Xu A, Lam KS, Wong NS, Chen J, Shepherd PR and Wang Y. Cholesterol-induced mammary tumorigenesis is enhanced by adiponectin deficiency: role of LDL receptor upregulation. Oncotarget. 2013; 4:1804-1818. doi: 10.18632/oncotarget.1364.

128. Jones RG, Plas DR, Kubek S, Buzzai M, Mu J, Xu Y, Birnbaum MJ and Thompson CB. AMP-activated protein kinase induces a p53-dependent metabolic checkpoint. Mol Cell. 2005; 18:283-293.

129. Jones RG, Plas DR, Kubek S, Buzzai M, Mu J, Xu Y, Birnbaum MJ and Thompson CB. AMP-activated protein kinase induces a p53-dependent metabolic checkpoint. Mol Cell. 2005; 18:283-293.

130. Lee HP, Lin CY, Shih JS, Fong YC, Wang SW, Li TM and Tang $\mathrm{CH}$. Adiponectin promotes VEGF-A-dependent angiogenesis in human chondrosarcoma through PI3K, Akt, mTOR, and HIF-alpha pathway. Oncotarget. 2015; 6:36746-36761. doi: 10.18632/oncotarget.5479.

131. Huang B, Cheng X, Wang D, Peng M, Xue Z, Da Y, Zhang N, Yao Z, Li M, Xu A and Zhang R. Adiponectin promotes pancreatic cancer progression by inhibiting apoptosis via the activation of AMPK/Sirt1/PGC-1alpha signaling. Oncotarget. 2014; 5:4732-4745. doi: 10.18632/ oncotarget.1963.

132. Stroup DF, Berlin JA, Morton SC, Olkin I, Williamson GD, Rennie D, Moher D, Becker BJ, Sipe TA and Thacker SB. Meta-analysis of observational studies in epidemiology: a proposal for reporting. meta-analysis of observational studies in epidemiology (MOOSE) group. JAMA. 2000; 283:2008-2012.

133. Stang A. Critical evaluation of the Newcastle-Ottawa scale for the assessment of the quality of nonrandomized studies in meta-analyses. Eur J Epidemiol. 2010; 25:603-605. 